University of Louisville

ThinkIR: The University of Louisville's Institutional Repository

$12-2018$

\title{
Synthesis and characterization of targeted bar encapsulated polylactic-co-glycolic acid nanoparticles to inhibit porphyromonas gingivalis biofilm formation.
}

Ranjith Radha Krishnan

University of Louisville

Follow this and additional works at: https://ir.library.louisville.edu/etd

Part of the Immunology and Infectious Disease Commons, Microbiology Commons, Nanotechnology Commons, Oral Biology and Oral Pathology Commons, and the Periodontics and Periodontology

Commons

\section{Recommended Citation}

Radha Krishnan, Ranjith, "Synthesis and characterization of targeted bar encapsulated polylactic-coglycolic acid nanoparticles to inhibit porphyromonas gingivalis biofilm formation." (2018). Electronic Theses and Dissertations. Paper 3125.

https://doi.org/10.18297/etd/3125

This Master's Thesis is brought to you for free and open access by ThinkIR: The University of Louisville's Institutional Repository. It has been accepted for inclusion in Electronic Theses and Dissertations by an authorized administrator of ThinkIR: The University of Louisville's Institutional Repository. This title appears here courtesy of the author, who has retained all other copyrights. For more information, please contact thinkir@louisville.edu. 
SYNTHESIS AND CHARACTERIZATION OF

TARGETED BAR ENCAPSULATED POLYLACTIC-CO-GLYCOLIC ACID

NANOPARTICLES

TO INHIBIT PORPHYROMONAS GINGIVALIS BIOFILM FORMATION

\author{
By \\ Ranjith Radha Krishnan, BDS
}

\begin{abstract}
A Thesis
Submitted to the Faculty of the School of Dentistry

in Partial Fulfillment of the Requirements

for the Degree of
\end{abstract}

Master of Science in Oral Biology

Department of Oral Immunology and Infectious Diseases

School of Dentistry

University of Louisville

Louisville, KY

December 2018 
Copyright 2018 by Ranjith Radha Krishnan

All rights reserved 

SYNTHESIS AND CHARACTERIZATION OF

TARGETED BAR ENCAPSULATED POLY LACTIC-CO-GLYCOLIC ACID

NANOPARTICLES

TO INHIBIT PORPHYROMONAS GINGIVALIS BIOFILM FORMATION

\author{
By \\ Ranjith Radha Krishnan
}

Thesis approved on

April 13, 2017

By the following Thesis Committee:

Dr. Donald R. Demuth

Thesis Director

Dr. Jill M. Steinbach-Rankins

Co-mentor

Dr. Richard J. Lamont 


\section{DEDICATION}

To my beloved family 


\section{ACKNOWLEDGEMENTS}

I would like to sincerely thank every individual who has helped me throughout my research and thesis writing. It's their love, support and encouragement that has helped me to successfully complete this thesis.

Firstly, I would like to express my gratitude to my mentors Dr. Donald R. Demuth and Dr. Jill M. Steinbach-Rankins, you both have been tremendous mentors for me. I would like to thank you for encouraging my research and for allowing me to grow as a research scientist. Your motivation and advice on both research as well as on my career have been priceless. I would also like to thank Dr. Richard J. Lamont for serving as my committee member and giving his valuable suggestions. I would especially like to thank Dr. Douglas Darling, Program Director of Masters in Oral Biology for his constant support and encouragement.

I would like to thank my parents C. Radhakrishnan and P. C. Reena for their love and care which has not only motivated me but also helped me to grow as a better human being. I would also like to thank my sister and her family who has been tremendous inspiration and support throughout. 
I also extend my thanks to all my lab members at both Demuth lab and SteinbachRankins lab for their help and patience. Last but not the least I would like to thank all my friends and extended family who has always been kind and inspiring during my ups and downs. 


\section{ABSTRACT \\ SYNTHESIS AND CHARACTERIZATION OF \\ TARGETED BAR ENCAPSULATED POLY LACTIC-CO-GLYCOLIC ACID \\ NANOPARTICLES \\ TO INHIBIT PORPHYROMONAS GINGIVALIS BIOFILM FORMATION}

\section{Ranjith Radha Krishnan}

April 13, 2017

Periodontal disease is one of the most prevalent infectious diseases worldwide. Between $30-50 \%$ of the global adult population suffers from periodontal disease. Some form of periodontitis is present in $46 \%$ of American adults, corresponding to annual expenditures in excess of 14 billion dollars for treatment and prevention. Current treatments for periodontal diseases involve mechanical removal of plaque, correction of risk factors, gingival surgery and/or antibiotic therapy. To our knowledge there is no effective therapeutic approach that aims to limit pathogen colonization of the oral biofilm or recolonization after treatment. Interaction of the pathogen Porphyromonas gingivalis with oral streptococci is critical in the pathogenesis of periodontal diseases. Our previous studies identified a peptide (BAR) that potently inhibited this interaction and reduced $P$. gingivalis virulence in vivo. However, BAR required higher concentrations and prolonged exposure in limiting $P$. gingivalis in a pre-established biofilm. This study is aimed at developing targeted BAR encapsulated poly(lactic-co-glycolic acid; PLGA) nanoparticles (NPs) to increase the efficacy of BAR to inhibit $P$. gingivalis colonization in a dual species biofilm. NPs encapsulating BAR were synthesized using double emulsion solvent evaporation technique. We generated NPs with particle size of $207 \pm 19 \mathrm{~nm}$ and zeta potential of $-15 \mathrm{mV}$. 
Loading and controlled release properties of NPs were determined using a fluorescently labeled BAR. We showed that BAR-NPs had a total payload of $14.12 \pm 0.39 \mu \mathrm{g} / \mathrm{mL}$ of BAR per mg of NP, resulting in the sustained-release of BAR for up to 4 hours. Furthermore, NPs encapsulating BAR peptide potently inhibited pre-formed P.gingivalis/ S. gordonii biofilm. These results suggest that enhanced inhibition of $P$. gingivalis was be obtained with BAR-NPs, identifying a novel therapeutic approach to effectively targeting $P$. gingivalis colonization of the oral cavity. 
TABLE OF CONTENTS

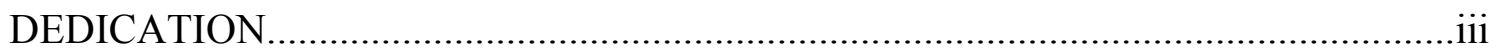

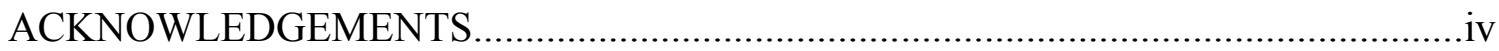

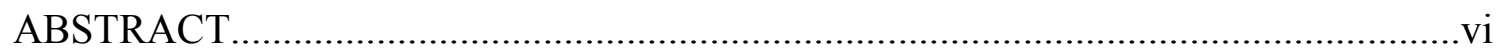

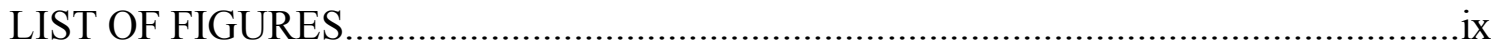

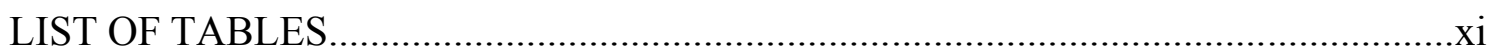

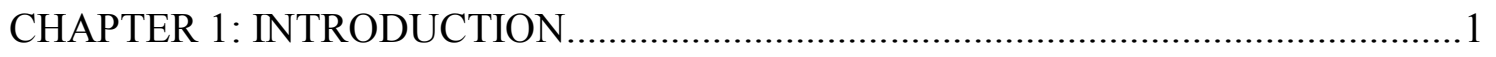

CHAPTER 2: HYPOTHESIS AND SPECIFIC AIMS ........................................... 13

CHAPTER 3: MATERIALS AND METHODS........................................................... 14

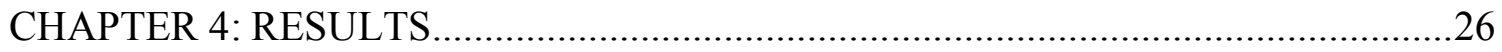

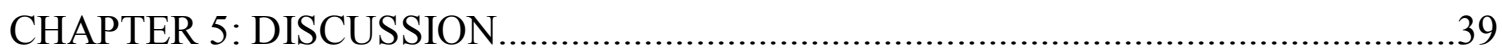

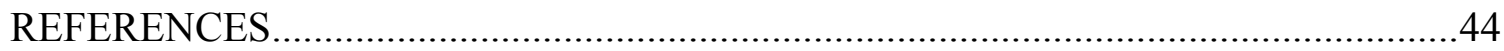

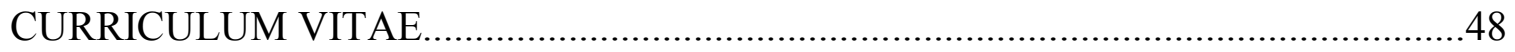




\section{LIST OF FIGURES}

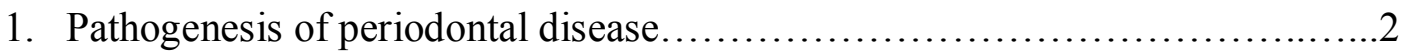

2. Stages of biofilm development...................................... 5

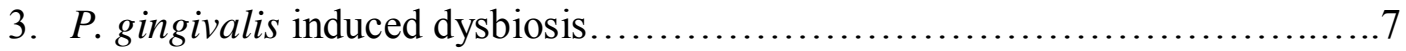

4. Mechanism of $P$. gingivalis $-S$. gordonii co-aggregation...................... 8

5. Schematic showing PLGA NP degradation............................. 10

6. Hydrolysis of PLGA.............................................. 10

7. Schematic representation of fimbrial structures of Actinomyces oris............11

8. Overview of double emulsion solvent evaporation technique for NP synthesis.. 16

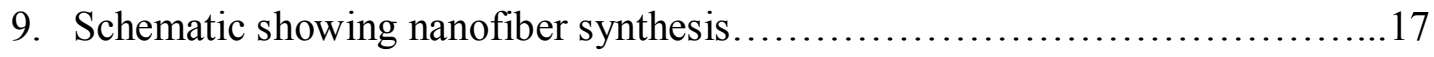

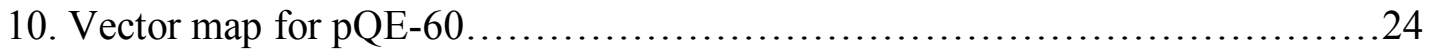

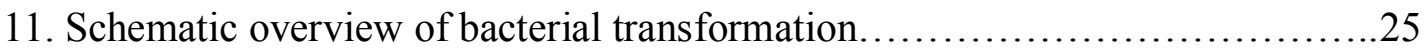

12. Ratio of $P$. gingivalis and $S$. gordonii microcolonies treated with BAR ........27

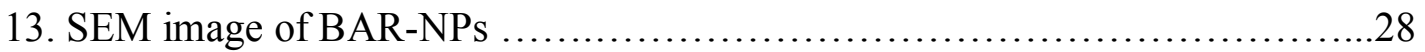

14.1. Dose dependent encapsulation of NPs...............................29

14.2. Dose dependent encapsulation efficiency of NPs.......................29

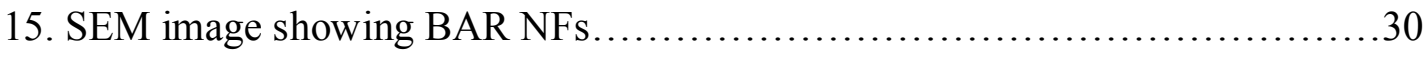

16.1. Total amount of BAR released per mg of NPs........................... 31

16.2. Percent release of NPs.............................................. 31

17.1. Total amount of BAR released per mg of NFs.......................... 32 
17.2. Percent release of NFs.

18. Confocal images showing biofilms treated with BAR-encapsulated NPs........35

19. Confocal images showing biofilms treated with BAR modified NPs............37

20. Ratio of $P$. gingivalis and $S$. gordonii in biofilms treated with BAR and NPs...37

21. Gel electrophoresis showing PCR products amplifying cafA gene..............38 


\section{LIST OF TABLES}

1. Sequence of BAR peptide..................................... 14

2. Primers used for amplification of $c a f A$ gene.........................22

3.1 PCR protocol used for amplification of $c a f A$ gene...................23

3.2 PCR cycling conditions used for amplification of $c a f A$ gene............23

4. Effect of prolonged exposure of BAR on dual species biofilm.........27

5. Effect of free BAR, sustained release-NPs and BAR-modified NPs on dual species biofilm......................................... 35 


\section{CHAPTER 1 \\ INTRODUCTION}

Periodontitis is defined as an inflammatory disease of the supporting tissues of the teeth caused by specific microorganisms or groups of microorganisms, resulting in progressive destruction of the periodontal ligament and alveolar bone with increased probing depth formation, gingival recession, or both (1). Periodontal disease is one of the most prevalent infectious diseases worldwide affecting between $30-50 \%$ of the global adult population suffers from periodontal disease (2-4). In America $46 \%$ of the adults suffer from some form of periodontal disease; corresponding to annual expenditures in excess of 14 billion dollars for treatment and prevention. An estimated $18 \%$ of the US population has moderate periodontitis and 7\% is afflicted by severe periodontitis (5). Studies have shown that periodontal disease occurs more often in patients with systemic disease like diabetes mellitus, AIDS, leukemia and Down's syndrome. Periodontal diseases are also proven to be risk factors for various systemic diseases such as infective endocarditis, cardiovascular disease, prosthetic device infection, diabetes mellitus, respiratory diseases, rheumatoid arthritis and adverse pregnancy outcomes (6-10).

\section{Development of dental plaque biofilms}

Periodontal disease starts with a microbial biofilm known as dental plaque. A milder form of periodontal disease which just exhibits inflammation of the gingiva is known as gingivitis. Maturation of biofilm within subgingival pocket together with hostsystemic and lifestyle factors cause attachment loss and lead to periodontitis. 


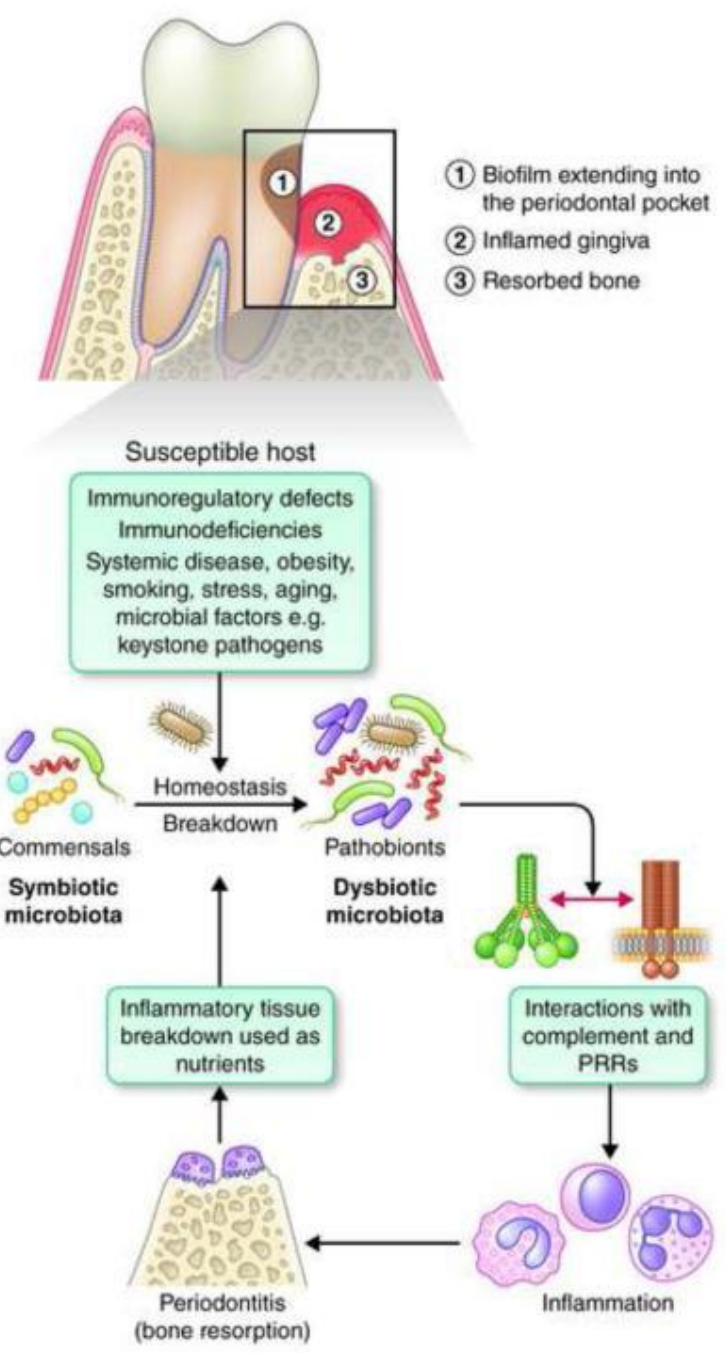

Fig 1. Pathogenesis of periodontal disease. (Hajishengallis, G. (2014). Immunomicrobial pathogenesis of periodontitis: keystones, pathobionts, and host response. Trends in immunology, 35(1), 3-11.)

A biofilm is a structured community of microbial cells attached to a surface and is enclosed in a polymeric matrix. In the oral cavity these surfaces can be teeth or restorative materials. During the initial stages of biofilm formation there is adsorption of salivary macromolecules on oral tissue surfaces which results in formation of the salivary pellicle. Bacteria can attach to this pellicle and actively grow (12). Bacterial cells participate in a communication process known as quorum sensing, that is an important pathway for biofilm maturation. Quorum sensing is a cell-cell communication process that involves signaling molecules called auto inducers (13) that allow bacteria to regulate gene expression in 
response to changes in cell-population density. Distinct stages in biofilm formation are: acquired pellicle formation, initial adhesion, maturation and dispersion (14).

The first step of biofilm formation is the attachment of an acquired pellicle. An acquired pellicle is a thin protein-containing film derived from salivary glycoproteins on the tooth surface. Interactions between various glycoproteins, other salivary components, and the tooth surface are involved in the formation of acquired pellicle. After formation the pellicle is ready for bacterial adhesion.

Bacterial adhesion to the pellicle is the second step of biofilm formation. Some of the planktonic bacteria recognize binding proteins like $\alpha$-amylase and proline-rich glycoproteins/proteins and bind to the pellicle. However, in this stage the attachment is reversible and those initially attached bacteria can detach from the pellicle easily. Early attachments are primarily based on electrostatic or physical attachments, but later, chemical forces become predominant (14). As the bacteria attach to the pellicle, they begin to secrete extracellular polymeric substances which helps the bacteria stay bound together and attached to the pellicle. Surface attachment structures including fimbriae and fibrils are the primary means through which bacteria attach to the pellicle Actinomyces spp, Streptococcus spp, Haemophilus spp, Capnocytophaga spp, Veillonella spp, and Neisseria are the main pioneer bacterial genera attaching to the tooth surface (15). Early colonization help these species occupy space and seize advantage in later competition with other species.

Later colonizing bacteria recognize polysaccharide or protein receptors on the pioneer bacterial cell surface and attach to them. Bacteria coaggregate, forming the typical corn cob forms, bristle brush forms, or other forms in mature oral biofilm. Later colonizing 
bacterial species include Fusobacterium nucleatum, Treponema spp, Tannerella forsythensis, $P$. gingivalis, Aggregatibacter actinomycetemcomitans (14). The microbial structure of a mature biofilm is significantly different from the initial biofilm, including a populational shift that occurs during biofilm development (17). Mature biofilms typically contain many porous layers and water channels through the biofilm, providing the bacteria essential nutrients (18). Moreover, cell aggregation is the basis of bacterial interactions in biofilm formation. Generally, one bacterial species can coaggregate with many other bacterial species by cell-to-cell recognition, but this aggregation is specific because one bacterial strain cannot aggregate with any random bacterial strains. The fundamental mechanism promoting this aggregation is via polysaccharide or protein recognition between bacteria (19).

In the mature biofilm, bacterial cells detach from the biofilm by single cell detachment or a group of cells detaching. Bacterial detachment is attributed to two reasons. The first is due to limited nutrients present at the original site, prompting the bacteria to identify and move to a new site with more nutrients for growth. This relocation can occur either by active dispersion or passive dispersion. Active dispersion is induced by the bacteria themselves, while passive dispersion is caused by other bacterial species which compete for the nutrient (20). The second reason for cell detachment is due to host defense processes, such as the shear force of saliva, which serves to limit biofilm growth (21). 


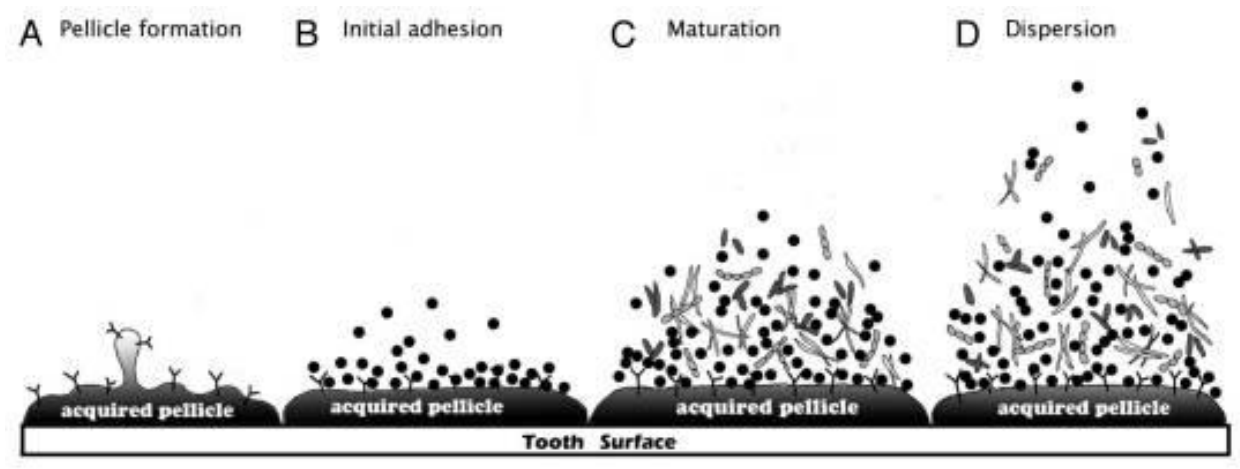

Fig 2. Stages of biofilm development. (Huang, R., Li, M., \& Gregory, R. L. (2011). Bacterial interactions in dental biofilm. Virulence, 2(5), 435-444.)

\section{$\underline{\text { Role of bacteria in Periodontitis }}$}

There are two main hypotheses regarding the role of bacteria in periodontal disease. The non-specific plaque hypothesis suggests that no one specific bacterial species is any more significant in causing periodontal disease, relative to another. According to this hypothesis, the accumulation of plaque results in oral diseases - not the individual bacteria or its virulence (22). The conclusion from this hypothesis indicates that since any plaque has the ability to cause disease, mechanical removal of plaque is an important step in disease prevention. In light of this theory all plaque was viewed as the cause and plaque control became the focus of periodontal therapy. The relative merits of this hypothesis is arguable since plaque associated diseases are polymicrobial infections, but in which only certain pathogens predominate. In contrast to this theory, the Specific plaque hypothesis proposes that only a few specific species are actively involved in disease pathogenesis (23). This hypothesis suggests that the primary concern is the specific bacteria that causes disease. As such, procedures are needed to remove only those species and not all the other species in the biofilm. However, this hypothesis could not explain the absence of pathogens in certain disease sites or the presence of pathogens in healthy sites. A more recent 
ecological plaque hypothesis combines the merits of both specific and non-specific plaque hypothesis. According to ecological plaque hypothesis, disease is a result of enrichment of some pathogens caused by ecological stress and an imbalance in the total microflora (22).

Dental biofilms are a complex community that may consist of more than 700 different bacterial species (24). Primary colonizing organisms that initiate the formation of the biofilm consists of Gram positive organisms such as streptococci and Actinomyces spp. Over the time there is a shift in microflora from Gram positive to Gram negative organisms and from facultative anaerobes to strictly anaerobic species (12). Populational shifts in the microflora can result in dysbiosis and are believed to cause periodontal disease. In subjects with periodontal disease, red complex are directly associated with periodontal disease and includes Tannerella forsythia, Porphyromonas gingivalis and Treponema denticola (25).

\section{$\underline{\text { Role of Porphyromonas gingivalis in Adult Periodontitis }}$}

P. gingivalis is a non-motile, asacchrolytic, rod shaped, Gram negative anaerobic bacterium which belongs to phylum Bacteriodetes. $P$. gingivalis was found in $87.75 \%$ of sub-gingival plaque samples obtained from patients with chronic periodontitis (26). $P$.

gingivalis produces a multitude of virulence factors which results in destruction of periodontal tissues by direct or indirect modulation of host inflammatory response (27). Hajishengallis et al, 2012 identified $P$. gingivalis as a keystone pathogen in the development of periodontal diseases in mice. Keystone pathogens are specific pathogens that when present even at low abundance can cause disease by altering a normal microbiota leading to disruption of normal host-microbe homeostasis (i.e., dysbiosis) (28). 


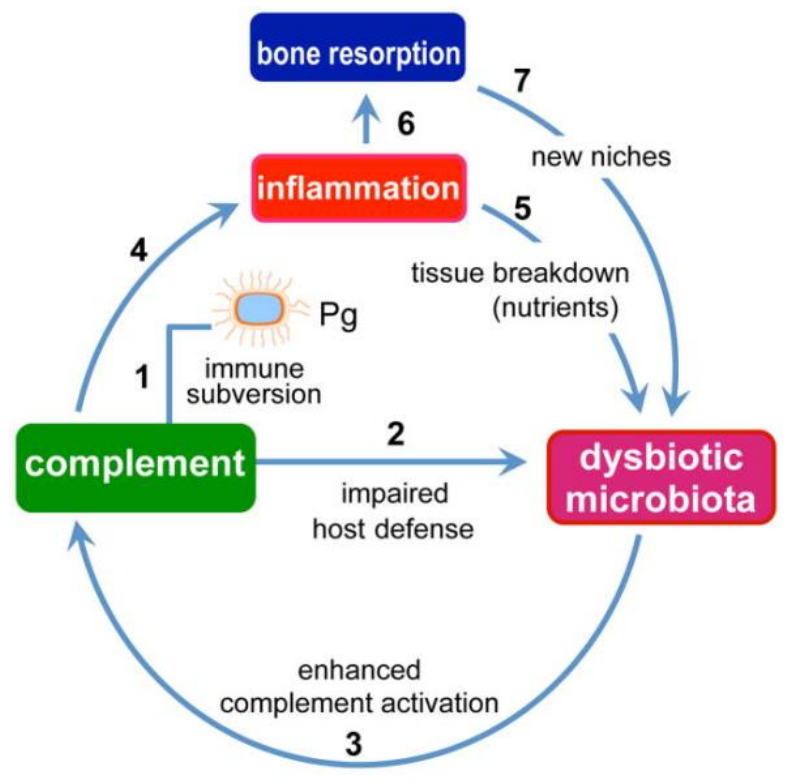

Fig 3. P. gingivalis induced dysbiosis. (Hajishengallis, G., Darveau, R. P., \& Curtis, M. A. (2012). The keystone-pathogen hypothesis. Nature Reviews Microbiology, 10(10), 717-725.)

\section{Porphyromonas gingivalis- Streptococcus gordonii interaction}

The primary niche of $P$. gingivalis in the oral cavity is the sub-gingival pocket. Before $P$. gingivalis colonizes the sub-gingival pocket it often adheres to primary colonizers of the oral cavity like Streptococcus gordonii (29). Previous studies have shown that adherence of $P$. gingivalis to oral streptococci is driven by a protein-protein interaction that occurs between the minor fimbrial antigen (Mfa) of $P$. gingivalis and the streptococcal antigen I/II (30). A region encompassing amino acids 1167 to 1250 of the SspB polypeptide of S.gordonii antigen I/II was shown to be essential for adherence of $P$. gingivalis (31-33). Subsequently, This region of SspB was compared with the corresponding region of the Streptococcus mutans antigen I/II and demonstrated that a protein determinant comprised

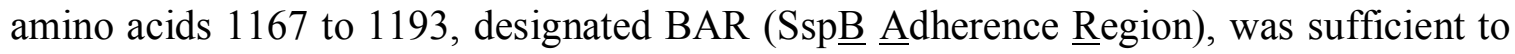
promote $P$. gingivalis adherence (34-36). A synthetic peptide encompassing this region of SspB functions as a potent inhibitor of $P$. gingivalis adherence to $S$. gordonii and its 
subsequent formation of biofilms in vitro $\left(\mathrm{IC}_{50}=1.3 \mu \mathrm{M}\right)$. BAR also inhibited $P$. gingivalis virulence and colonization of the oral cavity in vivo (37). These data suggest that the initial interaction between $P$. gingivalis and $S$. gordonii provides a potential target to prevent the colonization of $P$. gingivalis in the oral cavity and one can contemplate formulating BAR in an oral rinser or varnish to limit $P$. gingivalis colonization of the oral cavity. However, a possible limitation of this approach is that BAR can only be delivered transiently. Moreover, BAR-mediated disruption of pre-formed two-species biofilms or more complex three-species biofilms in vitro required a higher concentration of BAR, as well as a prolonged exposure. To address these challenges, the goal of this project was to develop methods to deliver higher localized concentration of BAR for a prolonged duration of time.
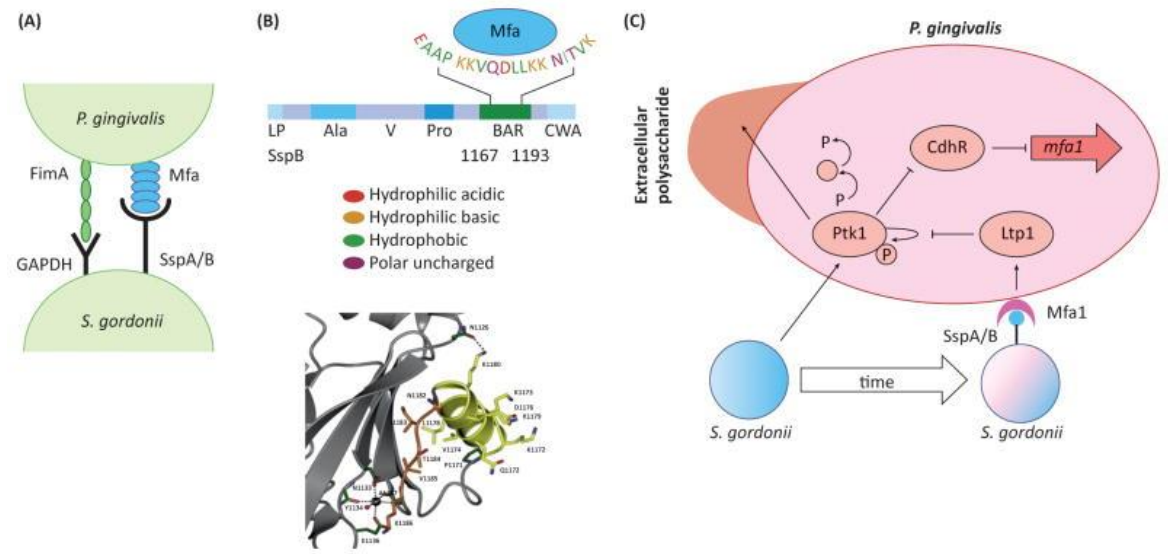

Fig 4. Mechanism of P. gingivalis - S. gordonii co-aggregation. (Lamont, R. J., \& Hajishengallis, G. (2015). Polymicrobial synergy and dysbiosis in inflammatory disease. Trends in molecular medicine, 21(3), 172-183.)

\section{Nanoparticles in oral diseases}

The use of nanotechnology in drug delivery has gained a lot momentum in the recent years (38). Nanoparticles are appealing vehicles to use for drug delivery because of their characteristic features like higher surface-to-volume ratio, their ability to encapsulate 
various hydrophobic and hydrophilic compounds. A variety of materials including dextran, gelatin, liposomes, fullerenes, metals, silica and polymers have been used to formulate nanoparticles. For drug delivery, it is often desirable for NPs to release the drug upon reaching the appropriate sites and hence, biodegradable formulations can aid in this endeavor. Poly(lactic acid,PLA), poly(lactic-co-glycolic acid, PLGA), polycaprolactone (PLCL) are all different biodegradable formulations that have been used for nanaoparticle synthesis (39).

In the last few decades PLGA has been most widely accepted and studied for drug delivery and tissue engineering applications. PLGA is a family of FDA-approved biodegradable polymers that are highly biocompatible and have been extensively used as controlled delivery vehicles for drugs, proteins, and various other macromolecules such as DNA and RNA (40-42). Favorable degradation characteristics, sustained-release properties, and surface modification has made PLGA a popular candidate for NP formulations. In addition, mechanical strength and ability to undergo hydrolysis can be altered by controlling parameters like molecular weight and the monomer ratio of ratio of lactic to glycolic acid (43).

PLGA degradation is a collective process of bulk diffusion, surface diffusion, bulk erosion and surface erosion. The initial burst of active agent during the release from nanoparticles is dependent on the drug and polymer hydrophobicity. In the second phase, the drug is gradually released as water hydrolyzes the polymer into oligomeric and monomeric products (43-44). 


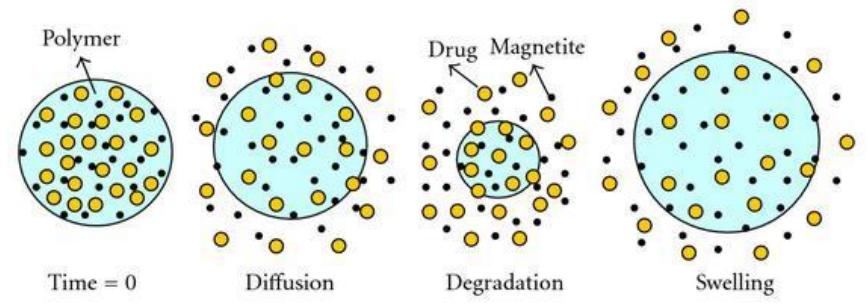

Fig 5. Schematic showing PLGA NP degradation. (Asmatulu, R., Fakhari, A., Wamocha, H. L., Chu, H. Y., Chen, Y. Y., Eltabey, M. M., ... \& Ho, J. C. (2009). Drug-carrying magnetic nanocomposite particles for potential drug delivery systems. Journal of Nanotechnology, 2009.)

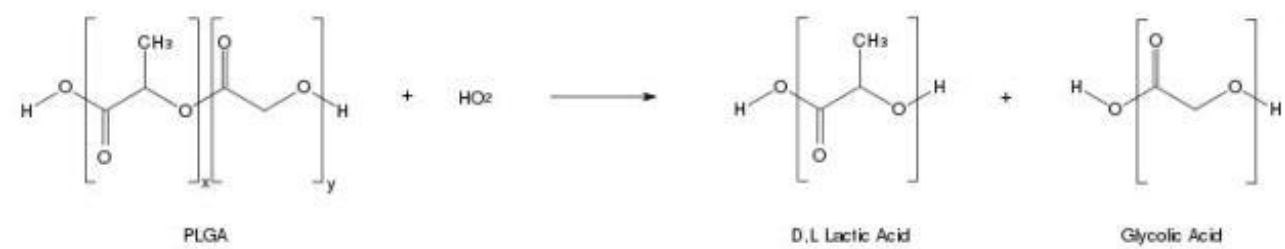

Fig 6. Hydrolysis of PLGA. (Makadia, H. K., \& Siegel, S. J. (2011). Poly lactic-co-glycolic acid (PLGA) as biodegradable controlled drug delivery carrier. Polymers, 3(3), 1377-1397.)

\section{$\underline{\text { Nanofibers }}$}

In the recent years polymer nanofibers (NFs) have been used in drug delivery due to their ease in synthesis, primarily through an electrospinning process. Various drugs, proteins, RNA, DNA and growth factors have been incorporated into electrospun fibers (45-47). PLGA nanofibers have been shown to increase the efficacy of various drugs. Combined with the above mentioned properties and the ability to use it under a periodontal pack after a surgery makes nanofibers a suitable candidate for treatment of periodontal diseases (48).

\section{CafA adhesin and targeting the nanoparticles}

Targeting of NPs are has been widely used in drug delivery to improve the local concentration of the drug. One method of achieving targeting is to surface modify NPs with proteins or drugs to achieve specific targeting or binding properties. In addition to 
specifically targeting delivery to particular niches (here in the oral cavity), surface modification may decrease the initial release of encapsulant from the NPs, aiding in prolonged release (49-51). Basic rationale here is to use a bacterial surface protein that can aid in targeting these NPs to the areas in oral cavity where $P$. gingivalis is present. To achieve this, we envision the use of CafA adhesin. CafA or coaggregation factor A is one of the 14 cell surface proteins of Actinomyces oris that possess the LPXTG anchoring motif that is recognized by sortase. CafA adhesin allows for Actinomyces/Streptococcus coaggregation (52). Surface modification of NPs with CafA represents an approach to target NPs or fibers to streptococcal cells, a primary initial niche of $P$. gingivalis in the oral cavity.

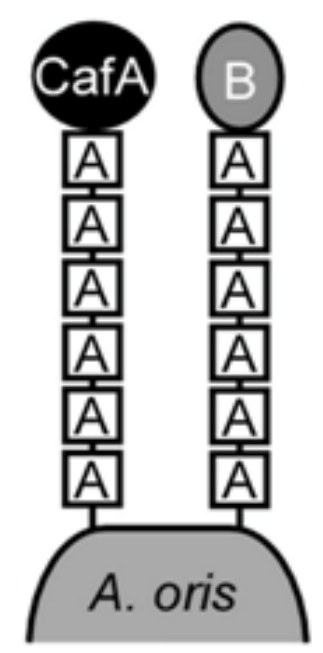

Fig 7. Schematic representation of fimbrial structures of Actinomyces oris. (Reardon-Robinson, M. E., Wu, C., Mishra, A., Chang, C., Bier, N., Das, A., \& Ton-That, H. (2014). Pilus hijacking by a bacterial coaggregation factor critical for oral biofilm development. Proceedings of the National Academy of Sciences, 111(10), 3835-3840.)

\section{BAR-modified PLGA Nanoparticles}

Previous studies in our lab has shown that BAR-modified NPs potently inhibit $P$. gingivalis adherence to $S$. gordonii. When administered simultaneously with $P$. gingivalis, BAR-modified NPs exhibited an $\mathrm{IC}_{50}$ to $0.3 \mu \mathrm{M}$ which is significantly lower when 
compared to $\mathrm{IC}_{50}$ of $1.3 \mu \mathrm{M}$ for free BAR peptide. However, in the oral cavity there is presence of well-established and complex biofilms. Hence it is important to know if BARmodified NPs are more potent in such conditions. Parallel to this study that seek to evaluate the efficacy of CafA modified NPs, we also intend to test the efficacy of BAR-modified NPs in an established $P$. gingivalis/ S. gordonii biofilm and compare them with free BAR. 


\section{CHAPTER 2}

\section{HYPOTHESIS AND SPECIFIC AIMS}

\section{$\underline{\text { Research Hypothesis }}$}

We hypothesize that the delivery of BAR by sustained release PLGA (poly lacticco-glycolic acid) nanoparticles (NPs) that are targeted to specific niches in oral cavity will increase the effectiveness of BAR against the colonization of $P$. gingivalis in the oral cavity.

\section{$\underline{\text { Specific Aims }}$}

1. Synthesize and characterize PLGA NPs that encapsulate BAR to provide prolonged-release of the peptide.

2. Target the BAR-NPs to specific niches to the oral cavity using CafA adhesin.

3. Determine the functional efficacy of NPs on an established biofilm. 


\section{CHAPTER 3}

\section{METHODS}

\section{Peptide Synthesis}

The BAR peptide used in this study, is shown in Table 1. The peptide is comprised of residues 1167 to 1193 of the SspB (Antigen I/II) protein sequence of S. gordonii. The peptide was synthesized by BioSynthesis, Inc. (Lewisville, TX) and was obtained at more than $90 \%$ purity.

Table 1. Sequence of BAR peptide.

\begin{tabular}{|l|l|}
\hline Peptide & Peptide Sequence \\
\hline BAR & NH2-LEAAPK $\underline{K}$ VQDLLKKANITVKGAFQLFS-OH \\
\hline
\end{tabular}

To assess the amount of BAR encapsulated within the NPs, a peptide designated as F-BAR was synthesized (BioSynthesis, Inc.) and 6-carboxyfluorescein was covalently attached to the epsilon amine of the lysine residue (underlined in Table 1).

Peptide containing a covalently attached biotin at its $\mathrm{N}$-terminus was also synthesized and obtained at more than $85 \%$ purity. 


\section{Growth of Bacterial Strains}

P. gingivalis strain ATCC 33277 was grown in Trypticase soy broth media (TSBY media) (Difco) supplemented with $0.5 \%(\mathrm{w} / \mathrm{v})$ yeast extract, $1 \mu \mathrm{g} / \mathrm{ml}$ (final concentration) menadione, and $5 \mu \mathrm{g} / \mathrm{ml}$ (final concentration) hemin. TSBY media was reduced for 24 hours under anaerobic conditions consisting of $80 \% \mathrm{~N}_{2} \quad 10 \% \mathrm{CO}_{2} \quad 10 \% \mathrm{H}_{2}$. Next, $P$. gingivalis was inoculated into the medium and grown anaerobically for 48 hours at $37^{\circ} \mathrm{C}$. S. gordonii DL-1 was cultured aerobically without shaking in brain-heart infusion (BHI) broth supplemented with $1 \%$ yeast extract for 16 hours at $37^{\circ} \mathrm{C}$. A. viscosus (ATCC 43146 ) was grown anaerobically in Trypticase soy broth supplemented with 5\% defibrinated sheep blood. Media was reduced for 24 hours under anaerobic conditions consisting of $80 \% \mathrm{~N}_{2} 10 \% \mathrm{CO}_{2} 10 \% \mathrm{H}_{2}$. A. viscosus was inoculated to the reduced media and grown anaerobically for 24 hours at $37^{\circ}$ C. Bacterial plasmid was extracted using Wizard $\AA$ Genomic DNA Purification Kit (Promega). E. coli strains DH5 $\alpha$ and XL1 were grown in Luria-Bertani broth (LB) at $37^{\circ} \mathrm{C}$ overnight. The pQE-60 vector DNA was harvested from DH5 $\alpha$ cells using QIAprep ${ }^{\circledR}$ Spin Miniprep Kit (QIAGEN). Electrocompetent XL1 cells were harvested from the overnight culture and stored at $-80^{\circ} \mathrm{C}$ in $50 \mu \mathrm{L}$ aliquots.

\section{Nanoparticle Synthesis}

Nanoparticles encapsulating BAR or F-BAR were synthesized using a double emulsion solvent evaporation technique. One hundred milligrams of 50:50 PLGA crystals were dissolved in $2 \mathrm{~mL}$ dichloromethane (DCM) overnight. The following day the PLGA/DCM mixture was vortexed while adding $200 \mu \mathrm{L}$ of prepared mixture of BAR $(4.3 \mu \mathrm{g} / \mathrm{mg}$ of PLGA) in TE buffer. PLGA/DCM/peptide solution was sonicated to ensure 
homogeneity. To create the second emulsion, PLGA/DCM/peptide solution was added drop wise to $2 \mathrm{~mL} 5 \%$ PVA while vortexing. This mixture was then sonicated and added to $50 \mathrm{~mL} 0.3 \%$ PVA in DI water. The resulting solution was stirred for 3 hours on a stir plate to allow for excess DCM evaporation. After 3 hours the solution was transferred to tubes and centrifuged at $13,000 \mathrm{rpm}$ for 10 minutes. After each centrifugation, the supernatant was discarded and the pellets were re-suspended in $20 \mathrm{~mL}$ distilled water and centrifuged. After 2 washes, the NPs were resuspended in $5 \mathrm{~mL}$ distilled water and transferred to a cryotube. NPs were subsequently frozen at $-80^{\circ} \mathrm{C}$ for 2 hours and lyophilized for 48 hours. All NPs were stored at $-20^{\circ} \mathrm{C}$. F-BAR-NPs were synthesized in the similarly but were protected from light during the entire procedure to ensure minimal loss of fluorescence.

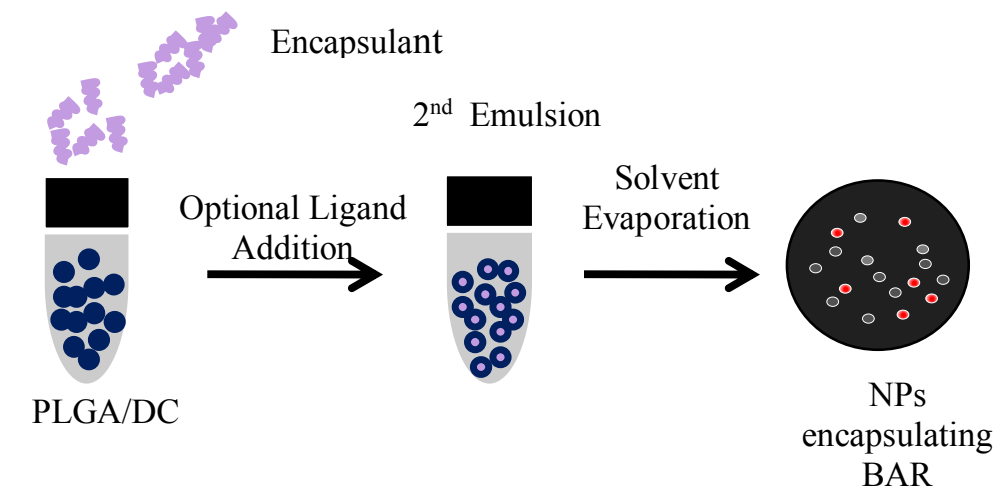

Fig 8. Overview of the double emulsion solvent evaporation technique for NP synthesis.

\section{Nanofiber synthesis}

In a scintillation vial, $120 \mathrm{mg}$ of 50:50 PLGA was dissolved in hexafluoroisopropanol (HFIP) overnight on a tabletop shaker. The day of synthesis BAR (4.3 $\mu \mathrm{g} / \mathrm{mg}$ of PLGA) in $200 \mu \mathrm{L}$ of TE was added to the PLGA/HFIP mixture. PLGA/HFIP/BAR solution was then transferred into a syringe which was then placed in the syringe driver. This emulsion was electrospun at a voltage of $20 \mathrm{mV}$ at a flowrate of 
$0.8 \mathrm{~mL}$ per hour. The voltage clip was attached to the syringe needle. The fine mist of solution was collected on a mandrel and allowed to dry for 15 minutes. After 15 minutes the fiber was removed from the mandrel using a razor blade and placed in a petri dish in a dessicator for 24 hours. After dessication, fibers were stored at $4^{\circ} \mathrm{C}$.

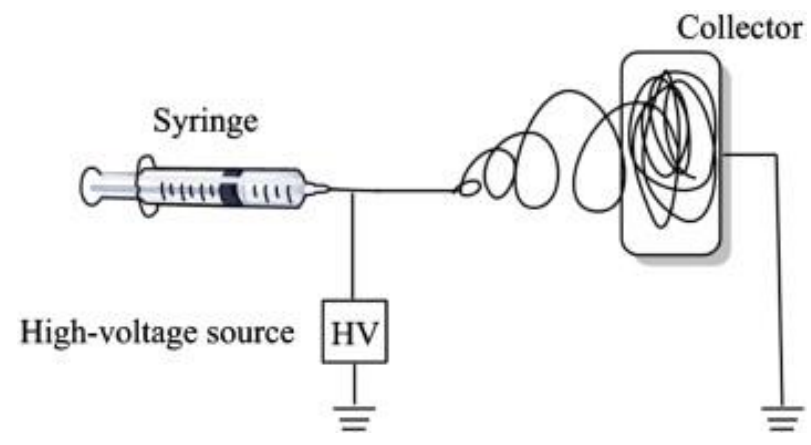

Fig 9. Schematic showing nanofiber synthesis. (Hu, X., Liu, S., Zhou, G., Huang, Y., Xie, Z., \& Jing, X. (2014). Electrospinning of polymeric nanofibers for drug delivery applications. Journal of Controlled Release, 185, 12-21.)

\section{$\underline{\text { BAR-Modified NPs }}$}

To synthesize BAR-modified PLGA NPs, the NP surfaces were first modified with avidin-palmitate to attach biotinylated BAR. Avidin-palmitate was synthesized as previously described (50). Briefly, $40 \mathrm{mg} / 4.8 \mathrm{~mL}$ solution of avidin was made in $2 \%(\mathrm{w} / \mathrm{v})$ sodium deoxycholate $(\mathrm{NaDC})$ in $\mathrm{PBS}$ and warmed to $37^{\circ} \mathrm{C}$. Four milligrams per four milliliter solution of palmitic acid-NHS (PA-NHS, Sigma) was prepared in $2 \%(\mathrm{w} / \mathrm{v})$ $\mathrm{NaDC}$ and sonicated until well-mixed. To the reaction vial containing avidin $3.2 \mathrm{~mL}$ of the above made PA-NHS solution was added dropwise, and reacted overnight at $37^{\circ} \mathrm{C}$. The following day, the reaction was dialyzed in $1200 \mathrm{~mL}$ of $0.15 \%(\mathrm{w} / \mathrm{v}) \mathrm{NaDC}$ in PBS heated to $37^{\circ} \mathrm{C}$ using a 3500 molecular weight cut off (MWCO) dialysis tubing to remove free 
PA-NHS. After overnight dialysis at $37^{\circ} \mathrm{C}$, complexed avidin-palmitate was transferred to a storage vial from the dialysis cassette and stored at $4^{\circ} \mathrm{C}$.

NPs were synthesized using an oil-in-water $(\mathrm{o} / \mathrm{w})$ single emulsion technique. 100 $\mathrm{mg}$ PLGA crystals were dissolved in $2 \mathrm{ml}$ of DCM overnight. The next day, $2 \mathrm{ml}$ of $5 \%$ (w/v) polyvinyl alcohol (PVA) solution was mixed with $2 \mathrm{ml}$ of $5 \mathrm{mg} / \mathrm{ml}$ avidin-palmitate to obtain a well-mixed solution. To create the single emulsion, $2 \mathrm{~mL}$ PLGA/DCM solution was added dropwise to $4 \mathrm{ml} \mathrm{PVA/avidin-palmitate} \mathrm{while} \mathrm{vortexing.} \mathrm{The} \mathrm{solution}$ was then sonicated to ensure homogeneity. This emulsion was then added to $50 \mathrm{~mL}$ of $0.3 \%$ PVA for 3 hours. to allow for the evaporation of excess DCM. The solution was then transferred to tubes and centrifuged at $13,000 \mathrm{rpm}$ at $4{ }^{\circ} \mathrm{C}$. Supernatant was discarded and the pellets were resuspended in $9 \mathrm{ml}$ distilled water. The resuspended NPs were incubated with biotinylated BAR for 30 minutes on a benchtop at a molar ratio of 3:1 BAR: avidin. NPs were washed and lyophilized as previously mentioned in the double emulsion technique and stored at $-20^{\circ} \mathrm{C}$.

\section{Physical Characterization of Nanoparticle/ Nanofiber}

Nanoparticle size and morphology were determined using scanning electron microscopy (SEM). NPs were mounted on a mounting pin with carbon tape and sputter coated with gold under vacuum. Average particle diameter and size distribution were determined from SEM images of at least 400 particles per batch using image analys is software (ImageJ, National Institutes of Health). Zeta potential was measured with a Zetasizer Nano ZS (Malvern) in $\mathrm{diH}_{2} \mathrm{O}$ to determine particle charge. Nanoparticles with a 
negative charge has less chances of aggregation. Nanofiber size, morphology and zeta potential were determined similarly.

\section{Functional Characterization of Nanoparticles}

To determine the total payload of the NPs, 2-3 mg of NPs were dissolved in $500 \mu \mathrm{L}$ of DCM. To this $500 \mu \mathrm{L}$ of TE buffer was added and vortexed for 1 min to extract the peptide into the aqueous solution. The solution was then centrifuged at 13,000 rpm for 5 minutes at $4^{\circ} \mathrm{C}$ and the aqueous phase is carefully removed without disturbing the organic phase. Five hundred microliters of TE buffer was added to the remaining organic phase and vortexed and centrifuged again to remove any remaining peptide. The amount of FBAR encapsulated was then determined by comparing fluorescence to a known standard of F-BAR in TE. The standard was plotted by serially diluting a $1 \mathrm{mg} / \mathrm{mL}$ solution of FBAR in TE. The standard and the NP samples were measured for fluorescence at 488/515 $\mathrm{nm}$ (excitation/emission).

To determine the sustained-release characteristics of BAR from the NPs, F-BAR NPs were added to $1 \mathrm{x}$ PBS and incubated at $37^{\circ} \mathrm{C}$ for 1 hour. After 1 hour the solution was centrifuged and supernatant was removed. To the remaining NPs fresh PBS was added and incubated until the next time point. This procedure was repeated and supernatants were obtained at 1, 2, 4, 8, 24, 48 and 72 hour time points. The amount of F-BAR released at each time point was measured by comparing to a known standard of F-BAR in PBS. The standard was plotted by serially diluting a $1 \mathrm{mg} / \mathrm{mL}$ solution of F-BAR in PBS. The standard and the NP samples were measured for fluorescence at 488/515 nm. 


\section{Functional Characterization of Nanofibers}

To determine the total payload of NFs, 2-3 mgs of NFs were dissolved in DMSO and compared to a known standard of F-BAR in DMSO. The NF samples and standards were measured for fluorescence at $488 / 515 \mathrm{~nm}$.

The sustained-release of BAR from NFs were determined similar to the sustained release of NPs as mentioned above.

\section{Dual Species Biofilm}

Formation of $P$. gingivalis/ S. gordonii biofilms were carried out as previously described (32). S. gordonii cells were harvested by centrifuging a $15 \mathrm{ml}$ culture of $S$. gordonii at $5600 \mathrm{rpm}$ for $5 \mathrm{~min}$. The supernatant was discarded and the cell pellet was resuspended in $1 \mathrm{ml}$ of $1 \mathrm{x}$ PBS. S. gordonii cells were labeled with $20 \mu \mathrm{l}$ of $10 \mathrm{mM}$ hexidium iodide for $15 \mathrm{~min}$ at room temperature on a rocker platform protected from light. After incubation the labeled samples were centrifuged at $5600 \mathrm{rpm}$ for $5 \mathrm{~min}$, the supernatant was discarded, and the cells were resuspended in $1 \mathrm{ml}$ of $1 \mathrm{x}$ PBS. Following this, the optical density (O.D) was measured at $600 \mathrm{~nm}$ to determine cell count. For all experiments, the optical density of $S$. gordonii cells was adjusted to 0.8 for uniformity of the $S$. gordonii cell amounts in each well. After adjusting the optical density, $1 \mathrm{ml}$ of $S$. gordonii cells were added to a 12 well culture plate containing a sterilized micro-coverslip in each well. The 12 well cell culture plate was wrapped in aluminum foil to protect the labeled cells from light and placed on a rocker platform in the anaerobic chamber at $37^{\circ} \mathrm{C}$ for 24 hours. $P$. gingivalis cultures used for biofilm formation were optimized using a similar approach. $15 \mathrm{ml}$ of $P$. gingivalis cells were centrifuged for $5 \mathrm{~min}$ at $5600 \mathrm{rpm}$. The 
supernatant was discarded and the cell pellet was resuspended in $1 \mathrm{ml}$ of prereduced $1 \mathrm{x}$ PBS. P. gingivalis cells were labeled with $15 \mu 1$ of carboxyfluorescein-succinylester (4 $\mathrm{mg} / \mathrm{ml})$. Cells were incubated with the fluorescent dye for $30 \mathrm{~min}$ on a rocker platform protected from light. Following incubation, cells were centrifuged at $5600 \mathrm{rpm}$ for $1 \mathrm{~min}$ and the supernatant was discarded. The pelleted cells were resuspended in $1 \mathrm{ml}$ of prereduced 1x PBS. Optical density of $P$. gingivalis cells were adjusted to 0.4 . After removal of unbound $S$. gordonii cells and washing, labeled $P$. gingivalis $(1 \mathrm{ml})$ cells were then added to each well of the microtiter plate. The 12 well cell culture plate was covered with aluminum foil and incubated at $37^{\circ} \mathrm{C}$ for 24 hours in an anaerobic chamber. Following incubation, the supernatant was removed from the wells of the 12 well cell culture plate and the treatment solutions containing free BAR or BAR-NPs in PBS were added to the appropriate wells and incubated for 1-3 hours. Following incubation the supernatant was removed and the wells were washed with pre-reduced 1x PBS to remove non-adherent bacterial cells. The cells were subsequently fixed with $4 \%(\mathrm{w} / \mathrm{v})$ paraformaldehyde, excess paraformaldehyde was removed, and the cells were washed with pre-reduced 1x PBS. The coverslip was then mounted on to a glass slide using Prolong Gold anti-fade reagent and viewed using confocal laser scanning microscopy.

\section{Confocal Microscopy}

P. gingivalis- S. gordonii biofilms were visualized using a Leica TCS SP8 confocal microscope (Leica Microsystems). The slides were viewed using an argon laser for visualization of FITC-labeled $P$. gingivalis and the $\mathrm{HeNe}-\mathrm{G}$ laser to visualize hexidium iodide- labeled streptococci. P. gingivalis binding was determined from randomly chosen 
frames using LAS X software. Z-stack images of the biofilms were obtained using a Z-step size of $0.7 \mu \mathrm{m}$.

\section{$\underline{\text { Image Analysis }}$}

The images obtained from confocal microscopy were processed and reconstructed into 3D images using the Volocity software. Images were imported into Volocity as .tiff files. Uniform filters were used to remove noise from the images and were further analyzed to quantify the extent of $P$. gingivalis binding. The image brightness and contrast was adjusted equally for all frames, and a snapshot of the image was captured. Next, the ratio of green to red fluorescence was determined. Each sample was analyzed in triplicate and 3 independent frames were measured for each well. Statistical significance between samples was determined using ANOVA. The variation was considered statistically significant when $\mathrm{P}<0.05$.

\section{$\underline{\text { Recombinant CafA expression in } E \text {. coli }}$}

Forward and reverse primers used for amplification of cafA gene are shown in Table 2.

Table 2. Primers used for amplification of cafA gene.

\begin{tabular}{|l|l|}
\hline Forward Primer & 5'- CAC CAT GGT GAT CGA CTG GAT CGA CTG -3' \\
\hline Reverse Primer & 5'- CAG ATC TGA TCT TGC CCA GCG C -3' \\
\hline
\end{tabular}

The cafA gene of A. viscosus (lacking the LPXTG anchoring motif) was amplified using the primers shown in Table 2 by PCR using Radiant ${ }^{\mathrm{TM}}$ HiFi Ultra Polymerase. PCR protocol and cycling conditions used were as described in Table 3. 
Table 3.1. PCR protocol used for amplification of the cafA gene.

\begin{tabular}{|l|l|l|}
\hline Component & $\begin{array}{l}\mathbf{5 0} \boldsymbol{\mu l} \\
\text { Reaction }\end{array}$ & $\begin{array}{l}\text { Final } \\
\text { Concentration/Notes }\end{array}$ \\
\hline RadiantTM 5x HiFi Ultra Reaction Buffer & $10 \mu \mathrm{l}$ & $1 \mathrm{X}$ \\
\hline Forward Primer $(10 \mu \mathrm{M})$ & $2.0 \mu \mathrm{l}$ & $400 \mathrm{nM}$ \\
\hline Reverse Primer $(10 \mu \mathrm{M})$ & $2.0 \mu \mathrm{l}$ & $400 \mathrm{nM}$ \\
\hline Template DNA & $1.0 \mu \mathrm{l}$ & $387 \mathrm{ng}$ \\
\hline RadiantTM HiFi Ultra Polymerase $(2 \mathrm{u} / \mu \mathrm{l})$ & $0.5 \mu \mathrm{l}$ \\
\hline PCR-grade water & $34.5 \mu \mathrm{l}$ \\
\hline
\end{tabular}

Table 3.2. PCR cycling conditions used for amplification of the cafA gene.

\begin{tabular}{|l|l|l|}
\hline \multicolumn{1}{|c|}{ Cycles } & Temperature \& Time & Notes \\
\hline 1 & $95^{\circ} \mathrm{C} 1$ minute & Initial Denaturation \\
\hline 30 & $95^{\circ} \mathrm{C} 15$ seconds & Denaturation \\
& $68^{\circ} \mathrm{C} 15$ seconds & Annealing \\
& $72^{\circ} \mathrm{C} 30$ seconds per $\mathrm{Kb}$ & Extension $1 \mathrm{~min} 30 \mathrm{~s}$ \\
\hline
\end{tabular}

PCR products were then concentrated using DNA Clean \& Concentrator ${ }^{\mathrm{TM}}-5$ (Zymo Research). The insert and vector DNA (pQE-60; Fig 10) were then digested using restriction endonucleases ( $\mathrm{NcoI}$ and $\mathrm{Bg} l \mathrm{II}$ ) to create sticky ends for ligation. The digested insert and vector DNA were then ligated using T4 DNA Ligase (New England BioLabs Inc.). 


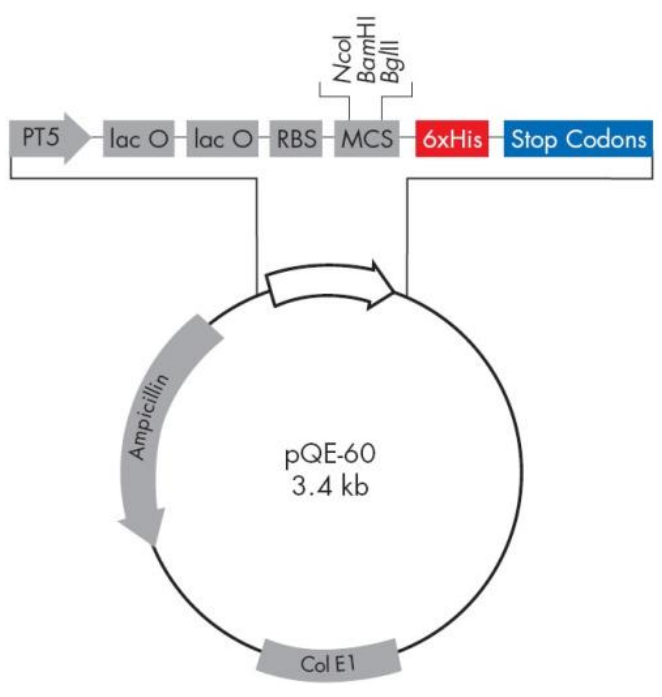

Fig 10. Vector map for $\mathrm{pQE}-60$.

Vector containing the desired insert was then transformed into XL1 electrocompetent cells by electroporation. The cells were allowed to grow in SOC medium containing no antibiotics at $37^{\circ} \mathrm{C}$ for $45 \mathrm{~min}$. Following this the cells were streaked on a LB agar plate containing tetracycline and ampicillin $(1 \mu \mathrm{L} / \mathrm{mL})$ and allowed to grow overnight at $37^{\circ} \mathrm{C}$ (Fig 11). Individual colonies were selected and passaged in LB broth containing tetracycline and ampicillin $(1 \mu \mathrm{L} / \mathrm{mL})$. 


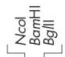
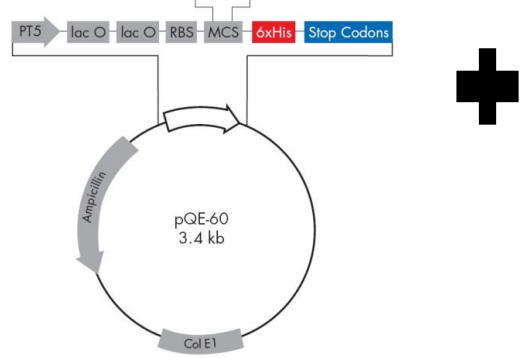

ANA_2230
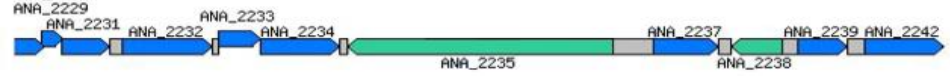

$\uparrow$

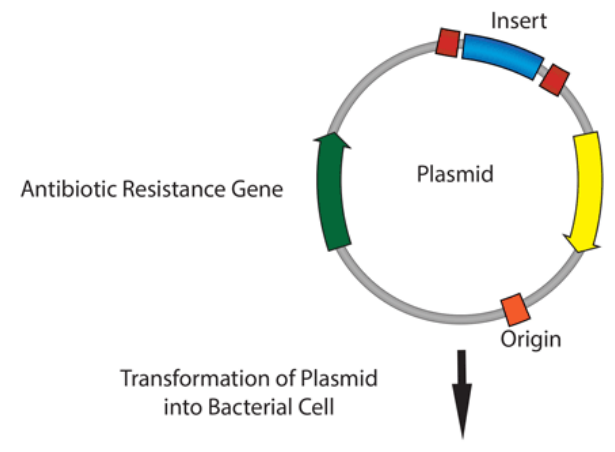

Plasmid in cell expresses antibiotic resistance gene

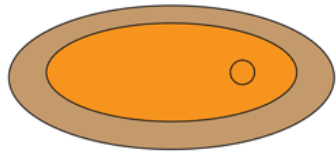

Plate cells on LB Agar Antibiotic

Only cells that contain the plasmid will be able to grow/divide and form colonies.

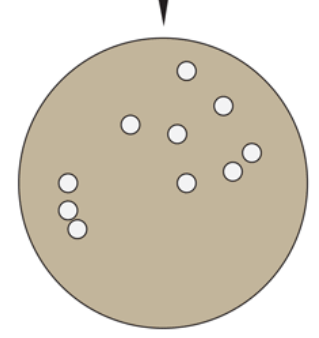

Fig 11. Schematic overview of bacterial transformation. (www.addgene.org) 


\section{CHAPTER 4}

\section{RESULTS}

\section{$\underline{B A R}$ requires prolonged exposure to inhibit established two species biofilm}

Previous studies have shown that BAR requires prolonged exposure ( $>60$ mins) to inhibit established three-species biofilm (29). To determine the time required by BAR to inhibit an established two-species biofilm, $3 \mu \mathrm{M}$ of free BAR was used to treat an established $P$. gingivalils/ S. gordonii biofilm for 1, 2 and 3 hours. $P$. gingivalis and $S$. gordonii microcolonies were then visualized by confocal scanning microscopy, and the number of microcolonies that formed per microscope field-of-view were recorded for each time point. As summarized in Table 4, treating the biofilm for 3 hours with BAR resulted in $\sim 55 \%$ inhibition of the $P$. gingivalis microcolonies. In contrast, treatment for 1 and 2 hours showed no significant inhibition of $P$. gingivalis $(\mathrm{P}>0.05)$. Figure 12 shows the ratio of $P$. gingivalis/S.gondonii microcolonies were statistically significant between the control and treatment groups at 3 hour time point. This lower ratio means more inhibition of $P$. gingivalis colonies. This experiment provides preliminary data that supports the hypothesis that sustained release NPs can increase BAR effectiveness against established biofilms by reducing the amount of $P$. gingivalis bound to $S$. gordonii. 


\begin{tabular}{|l|l|l|}
\hline Time in hours & \multicolumn{2}{|c|}{ Ratio between $P$. gingivalis and S. gordonii } \\
\hline & Control (Mean \pm SD) & Treated (Mean \pm SD) \\
\hline 1 & $0.23 \pm 0.009$ & $0.21 \pm 0.019$ \\
\hline 2 & $0.33 \pm 0.013$ & $0.31 \pm 0.013$ \\
\hline 3 & $0.33 \pm 0.006$ & $0.15 \pm 0.011$ \\
\hline
\end{tabular}

Table 4. Effect of prolonged exposure of BAR on the ratio between $P$. gingivalis and $S$. gordonii.

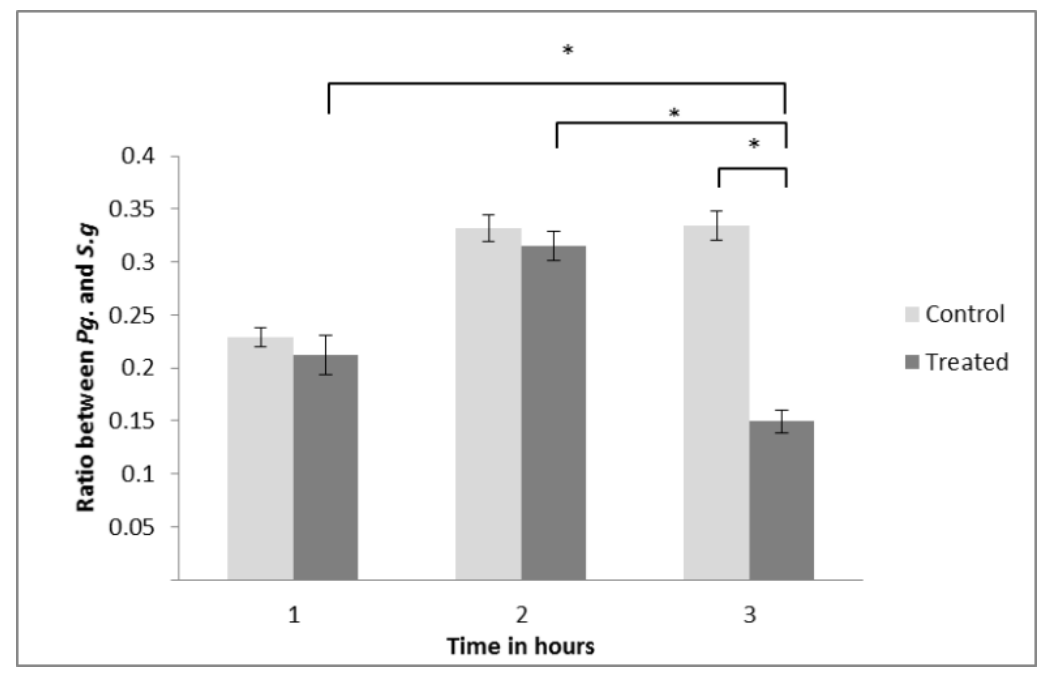

Fig. 12. Ratio of $P$. gingivalis and $S$. gordonii microcolonies treated with $3 \mu \mathrm{M}$ of BAR for 1,2 and 3 hours. *, the ratio was statistically significant $(\mathrm{P}<0.05)$

\section{Nanoparticle synthesis and characterization.}

Analysis of SEM images (Fig. 13) revealed that the average size of NPs are $207 \pm 19 \mathrm{~nm}$ and exhibit the expected spherical morphology. Zeta potential values for NPs were $-15 \mathrm{mV}$. 


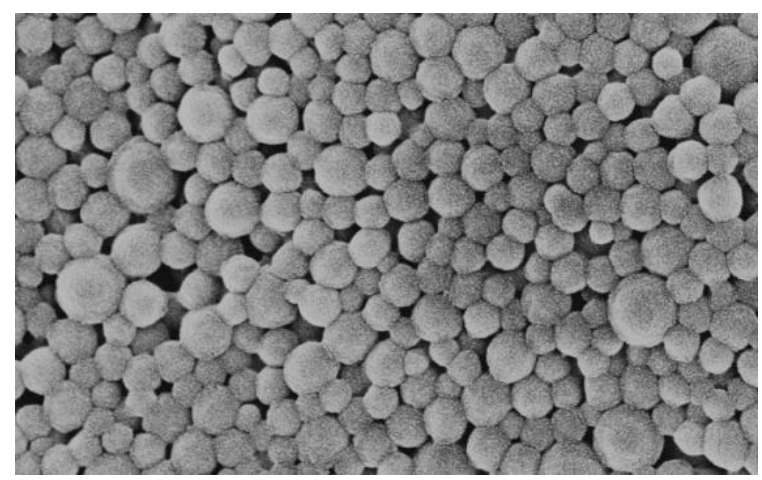

Fig 13. SEM image of BAR NPs

\section{Loading experiments}

In this experiment the amount of BAR encapsulated within the NPs was determined. Total fluorescence emitted by the NPs were converted to an amount of BAR by comparing the fluorescence to a known standard of F-BAR in TE. Loading experiments showed a total payload of $14.12 \pm 0.39 \mu \mathrm{g}$ of BAR per mg of NP. This corresponded to an encapsulation efficiency of $33 \%$.

\section{Dose dependent loading of nanoparticles}

To determine the dose dependent loading and encapsulation efficiency, NPs were synthesized using and initial concentration of $10 \mu \mathrm{g}, 21 \mu \mathrm{g}$ and $43 \mu \mathrm{g}$ per mg of PLGA.

Fig 14 shows the total payload and the encapsulation efficiency for each batch of NPs. There is no significant difference in the percent encapsulation efficiency $(\mathrm{P}>0.05)$, but there is a dose-dependent increase in the total amount of BAR encapsulated. This suggests that NPs can be synthesized with varying concentrations of BAR to achieve optimal loading. 


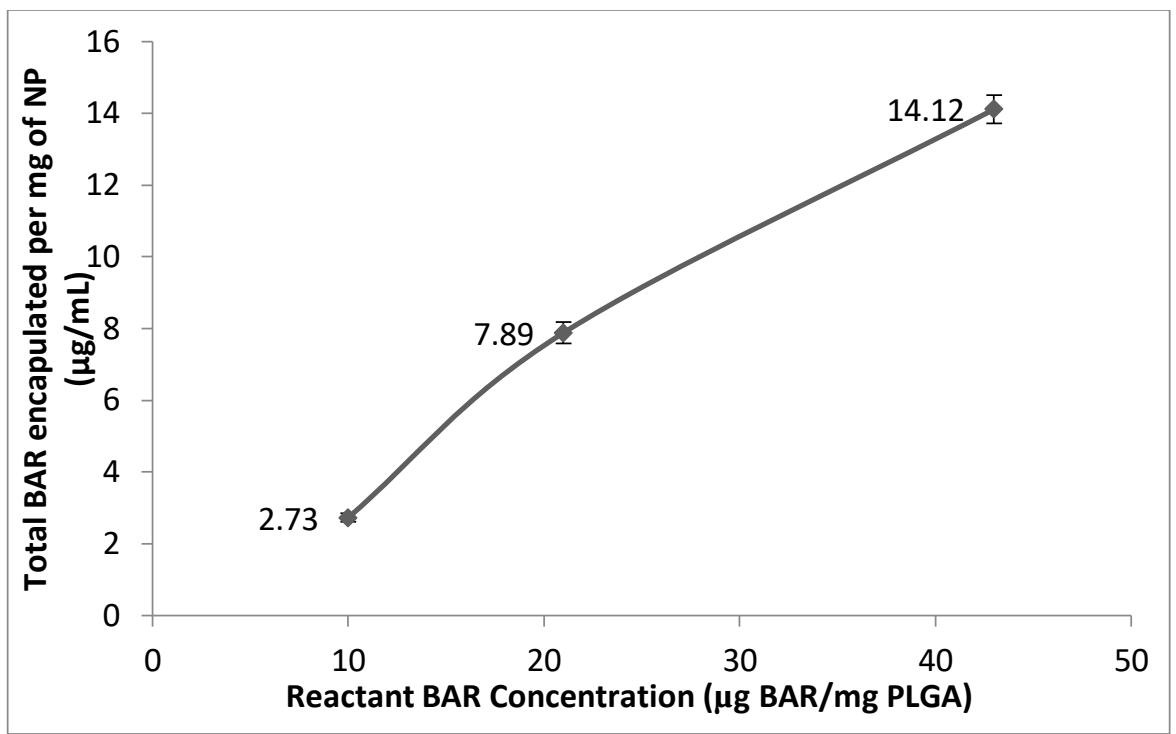

Fig 14.1. Dose dependent encapsulation of BAR.

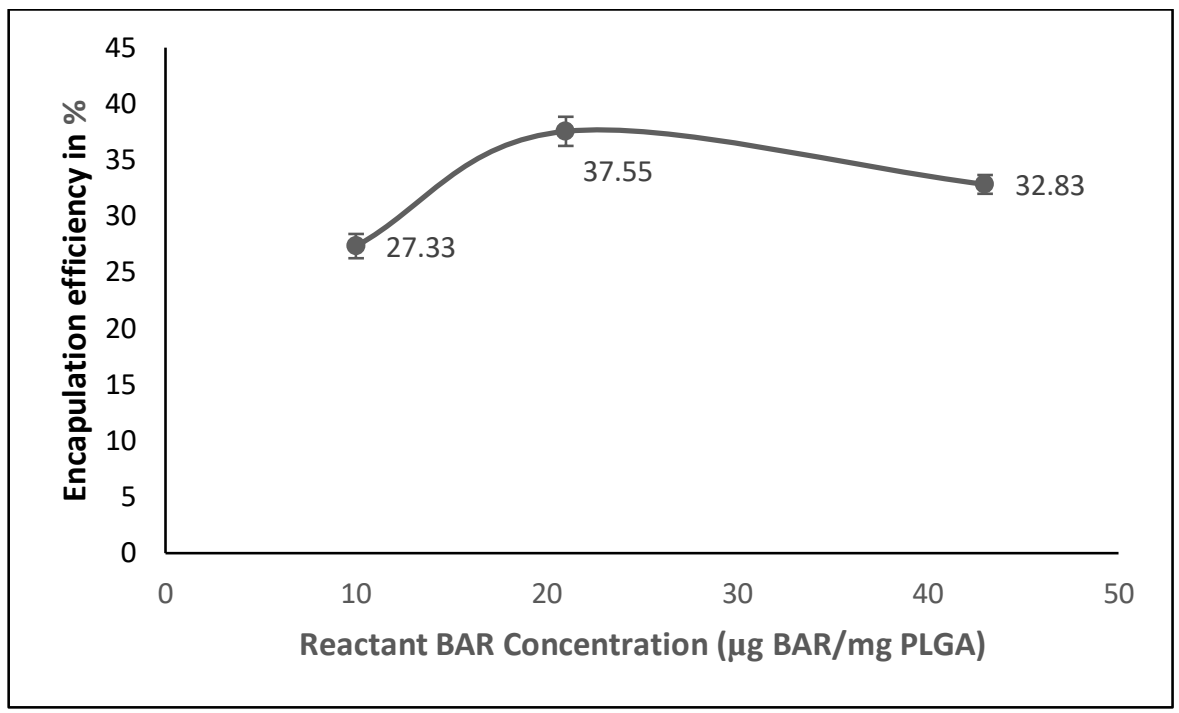

Fig 14.2. Dose dependent encapsulation efficiency of BAR. 


\section{Nanofiber characterization}

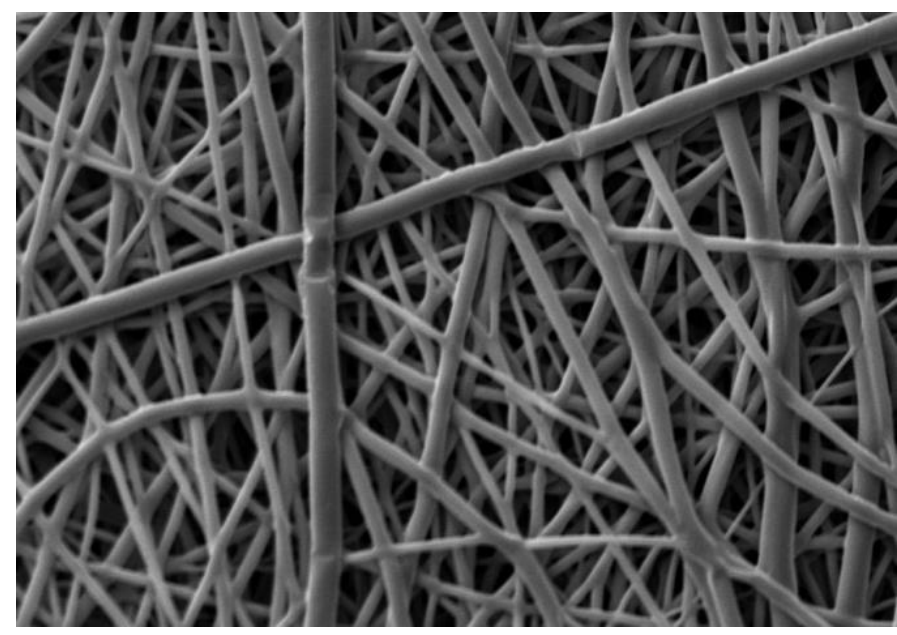

Fig 15. SEM image showing BAR NFs.

Similar to NPs, we validated the diameter and morphology of BAR NFs using SEM. Figure 15 depicts uniformly sized, well- delineated fibers with average size of $917 \pm 256 \mathrm{~nm}$. To determine the total pay load aliquots of NFs were dissolved in DMSO and the amount of fluorescence emitted was converted to an amount of BAR by comparing to known standards of F-BAR in DMSO. Loading experiment to determine the total amount of BAR encapsulated in the fibers showed an encapsulation of $46.8 \pm 0.63 \mu \mathrm{g}$ of BAR per mg of $\mathrm{NF}$, corresponding to an encapsulation efficiency of $92 \%$.

\section{$\underline{\text { BAR nanoparticles provide sustained release of BAR }}$}

For this experiment aliquots of BAR were incubated in PBS at $37^{\circ} \mathrm{C}$. Supernatant from various time points were used to measure the fluorescence. Triplicate fluorescence readings at each time points were compared to a known standard of F-BAR in PBS. Fig 16.1 shows the total concentration of BAR released at each time point over a 24 hour 
period. Fig 16.2 shows the percentage of encapsulated BAR released at each time point over a 24 hour period.

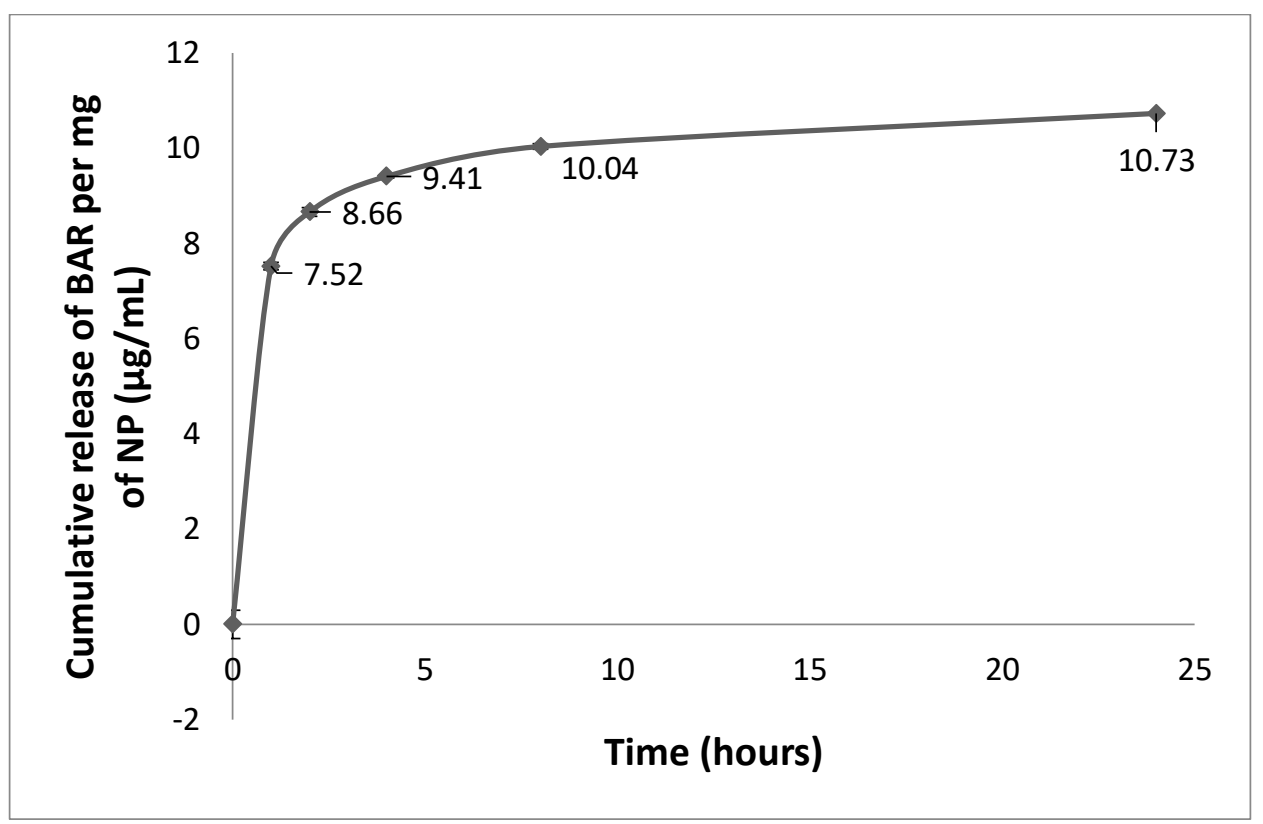

Fig 16.1. Total amount of BAR released per $\mathrm{mg}$ NPs over a 24 hour period.

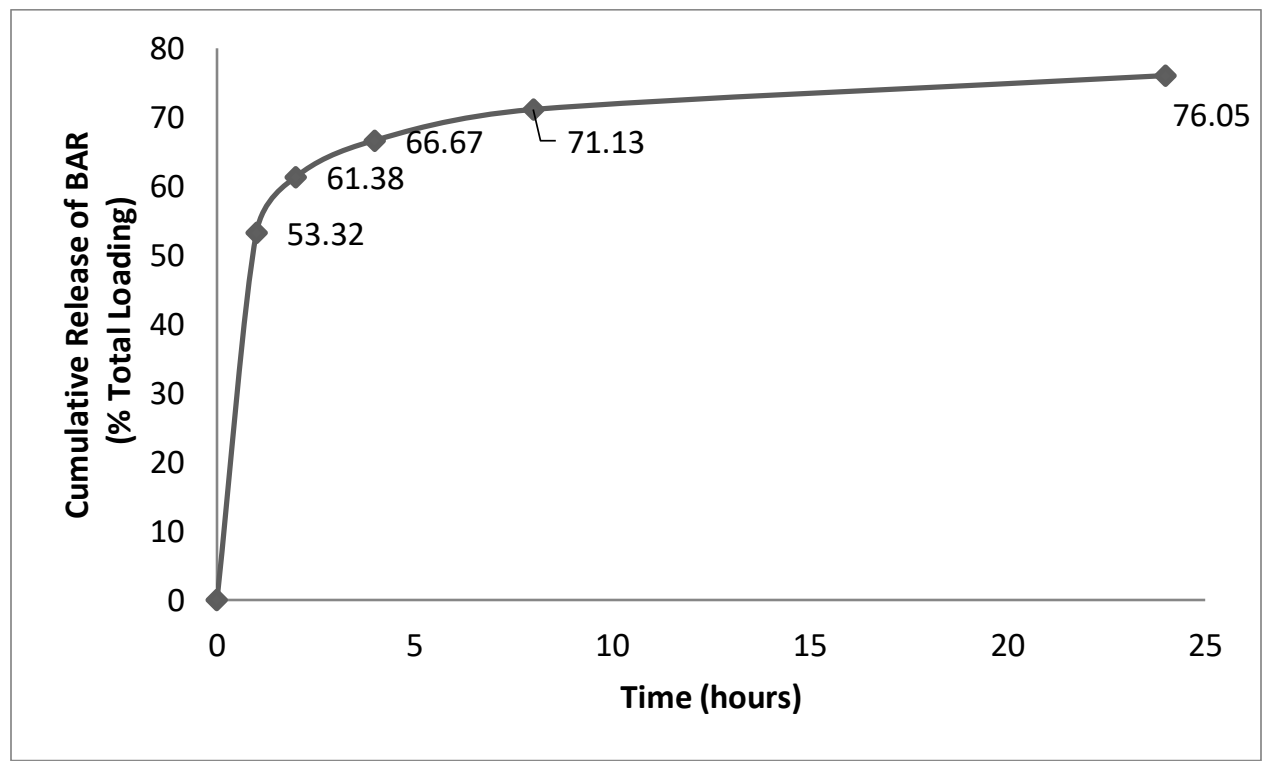

Fig 16.2. Percent of encapsulated BAR released per mg NPs over a 24 hour period. 


\section{Nanofibers provide sustained release of BAR in lower concentrations than NPs}

To determine the sustained-release of BAR, NFs were incubated with in PBS at $37^{\circ} \mathrm{C}$. Similar to NP sustained-release experiments, the supernatant from each release time point was assessed to determine the amount of BAR released. The amount of F-BAR released at each time points was compared to a known standard of F-BAR in PBS. Fig. 17.1 and 17.2 show the total amount of BAR and the percent encapsulate BAR, released at each time point over a 24 hour period, respectively. Although NFs showed a higher encapsulation per mg of fiber $(46.8 \pm 0.63 \mu \mathrm{g} / \mathrm{mg})$, relative to NP loading (14.12 $\pm 0.39 \mu \mathrm{g} / \mathrm{mg})$, less BAR was released over a 24 hour time period $(1.23 \mu \mathrm{g} / \mathrm{mg}$ vs. $10.7 \mu \mathrm{g} / \mathrm{mg})$

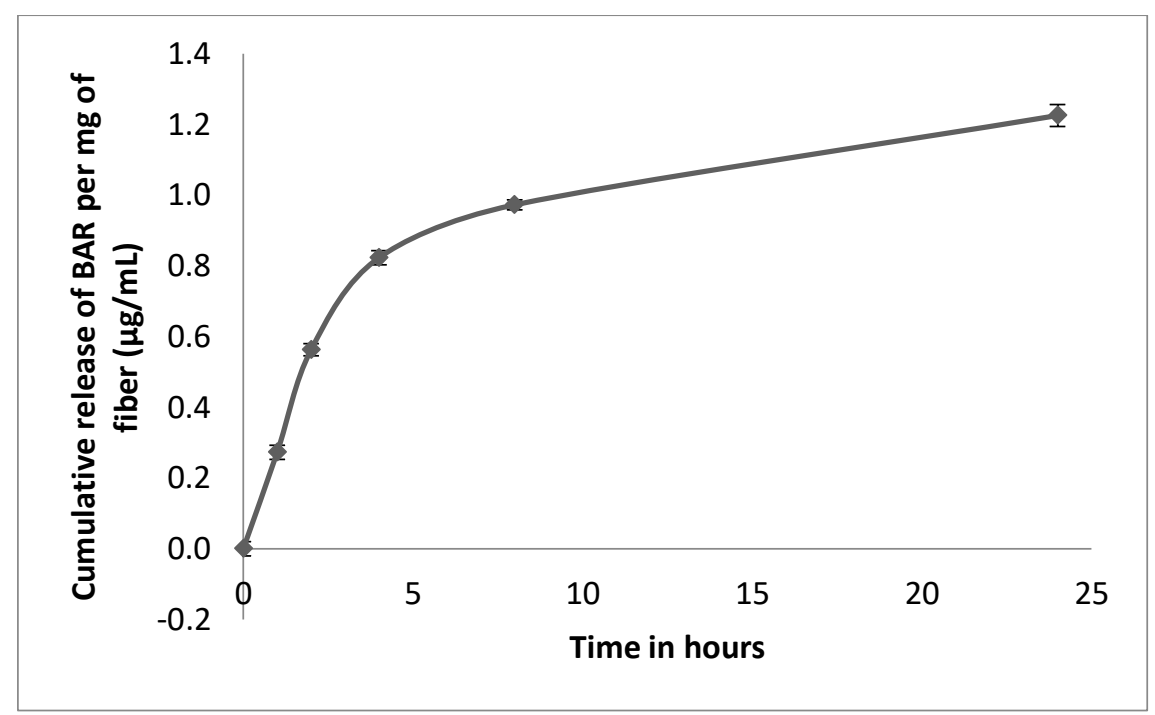

Fig 17.1. Total amount of BAR released per $\mathrm{mg}$ fiber over a 24 hour period. 


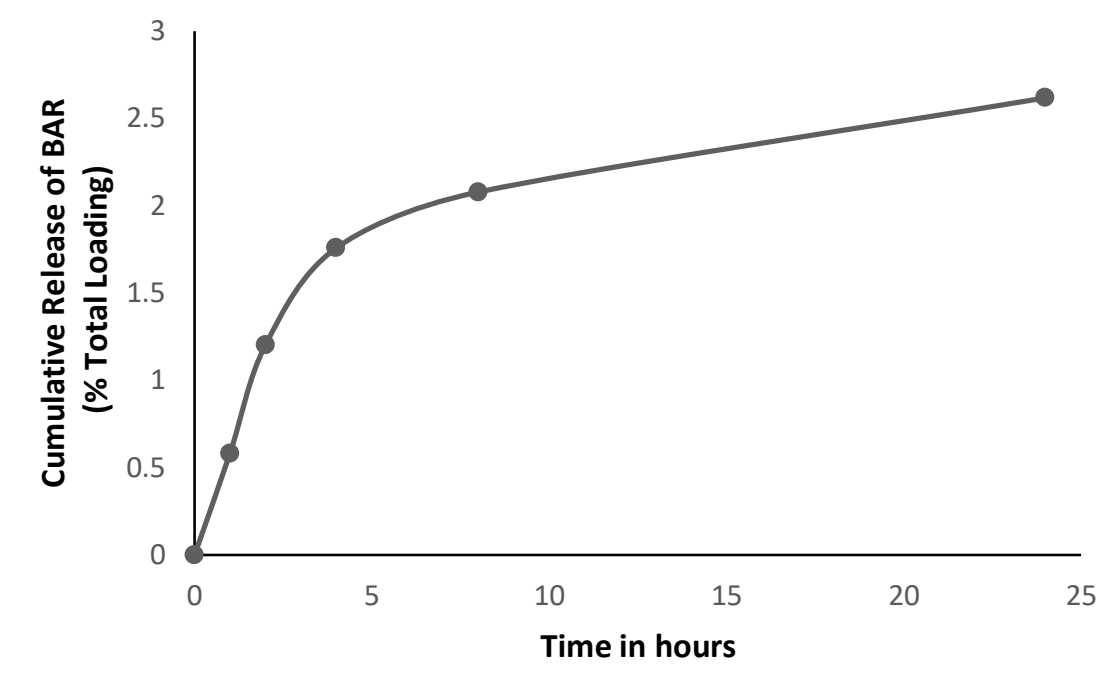

Fig 17.2. Percent of encapsulated BAR released per mg fiber over a 24 hour period.

\section{Sustained release BAR-NPs inhibit established $P$. gingivalis/S. gordonii biofilms.}

To determine if BAR-encapsulated NPs inhibit $P$. gingivalis on an established $P$. gingivalis/ S. gordonii biofilm, $P$. gingivalis biofilms were formed on immobilized streptococci. Various molar concentrations of BAR-NPs in PBS were used to treat the established biofilm for 1 hour. Sufficient amounts of NPs to deliver BAR peptide concentrations ranging from 0.3 to $3 \mu \mathrm{M}$ were tested and compared with $3 \mu \mathrm{M}$ of free soluble BAR. Only one concentration of soluble BAR $(3 \mu \mathrm{M})$ was used because the previous experiment showed $3 \mu \mathrm{M}$ of soluble BAR having no significant effect on established biofilms when treated for 1 hour. $P$. gingivalis/S. gordonii microcolonies were visualized using confocal scanning microscopy and the ratio of green ( $P$. gingivalis) and red (S. gordonii) fluorescence was quantified using Volocity image analysis software. For control reactions, the biofilms were treated with blank NPs for the same amount of time. The images of biofilms treated with BAR-NPs, soluble BAR or buffer alone are shown in Fig.18. As summarized in Table 5, BAR-NPs exhibited dose dependent inhibition of the 
dual species biofilm with the ratio of green to red fluorescence being significantly reduced $(\mathrm{P}<0.05)$ at $1.7 \mu \mathrm{M}$ and $3 \mu \mathrm{M}$. As expected $3 \mu \mathrm{M}$ soluble BAR had no effect on the ratio of green and red fluorescence. The striking result was that while soluble BAR required a prolonged exposure of 3 hours, BAR-NPs showed a significant reduction in the ratio of green and red fluorescence in just 1 hour.

Control

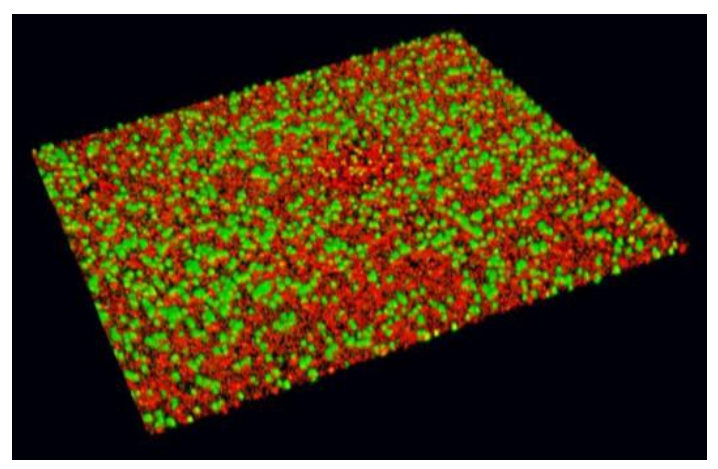

Free BAR $3 \mu \mathrm{M}$

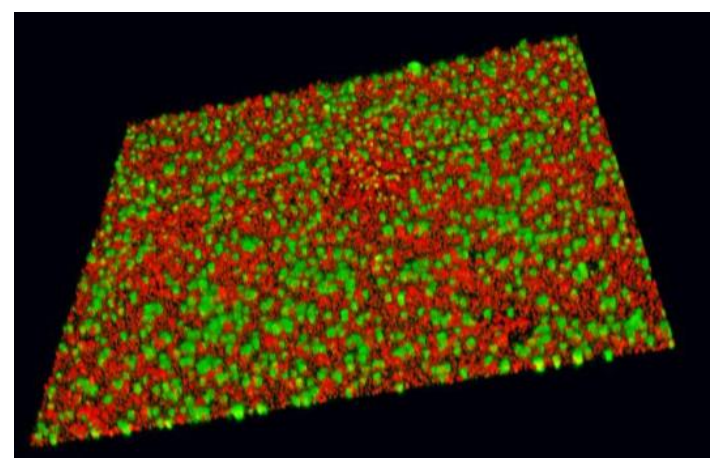

BAR-NP $0.3 \mu \mathrm{M}$

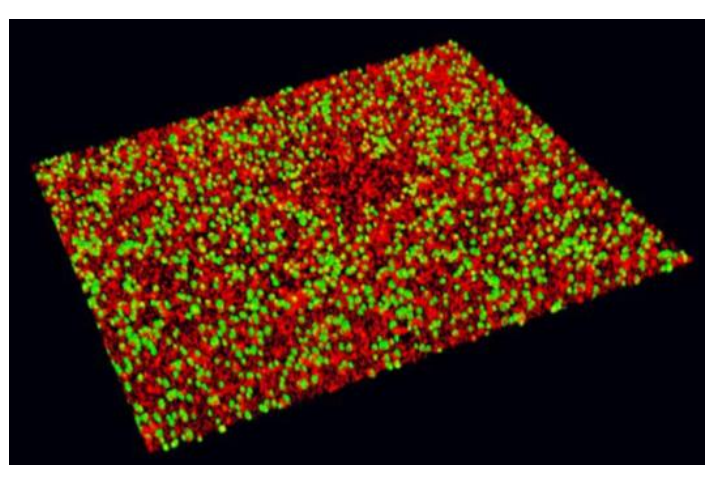


BAR-NP $1.7 \mu \mathrm{M}$

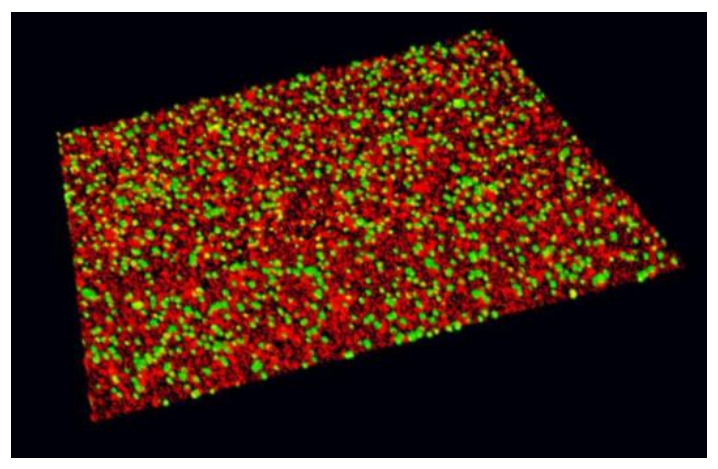

BAR-NP $3 \mu \mathrm{M}$

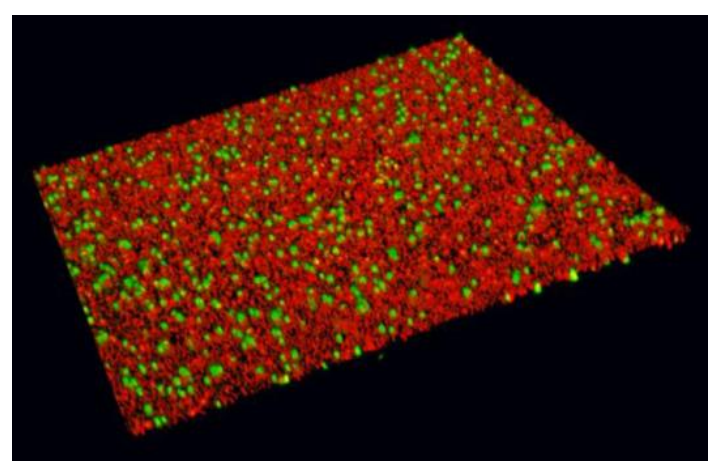

Fig. 18. Confocal microscopy images showing untreated, free BAR treated and BAR-encapsulated NP treated biofilms.

Table 5. Effect of free BAR, sustained release-NPs and BAR-modified NPs on the ratio between P.gingivalis and S. gordonii. Percentage inhibition in relation to the control is shown in ().

\begin{tabular}{|l|l|l|l|}
\hline & $\mathbf{0 . 3} \boldsymbol{\mu M}$ & $\mathbf{1 . 7} \boldsymbol{\mu M}$ & $\mathbf{3} \boldsymbol{\mu M}$ \\
\hline Control & & & $0.28 \pm 0.01$ \\
\hline Free BAR peptide & & & $0.26 \pm 0.02$ \\
& & & $(5 \%)$ \\
\hline Sustained-release & $0.25 \pm 0.01$ & $0.22 \pm 0.01$ & $0.13 \pm 0.00$ \\
BAR-NPs & $(6 \%)$ & $(17 \%)$ & $(51 \%)$ \\
\hline BAR-modified NPs & $0.27 \pm 0.01$ & $0.19 \pm 0.01$ & $0.11 \pm 0.01$ \\
& $(4 \%)$ & $(27 \%)$ & $(59 \%)$ \\
\hline
\end{tabular}




\section{BAR-modified NPs inhibit established $P$. gingivalis/ $S$. gordonii biofilms.}

Previously it was shown that BAR modified NPs competitively bind to $P$. gingivalis and prevent its initial colonization of the oral cavity (49). However in the oral cavity more complex and established biofilms are present. To determine if BAR modified NPs inhibit $P$. gingivalis on an established $P$. gingivalis/ $S$. gordonii biofilm, $P$. gingivalis biofilms were formed on immobilized streptococci. Various molar concentrations of BAR-modified NPs in PBS were used to treat the established biofilm for 1 hour. Sufficient amounts of NPs to deliver BAR peptide concentrations ranging from 0.3 to $3 \mu \mathrm{M}$ were tested. $P$. gingivalis/S. gordonii microcolonies were visualized using confocal scanning microscopy and the ratio of green ( $P$. gingivalis) and red ( $S$. gordonii) fluorescence was quantified using Volocity image analysis software. These results were then compared to control biofilms and biofilms treated with $3 \mu \mathrm{M}$ of soluble BAR. The images of biofilms treated with BAR modified NPs are shown in Fig.19. and quantified in Table 5, BAR-modified NPs exhibited dose dependent inhibition of the dual species biofilm with the ratio of green to red fluorescence being significantly reduced $(\mathrm{P}<0.05)$ at $1.7 \mu \mathrm{M}$ and $3 \mu \mathrm{M}$. Yet again the striking result was that while soluble BAR required a prolonged exposure of 3 hours, BAR-NPs showed a significant reduction in the ratio of green and red fluorescence in just 1 hour.

BAR modified NP $0.3 \mu \mathrm{M}$

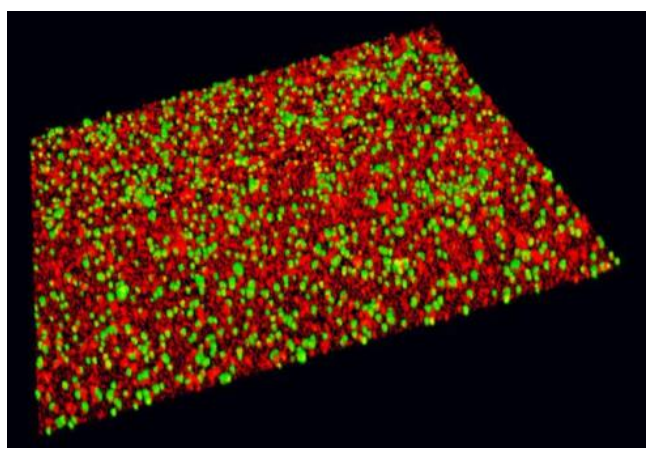


BAR modified NP $1.7 \mu \mathrm{M}$

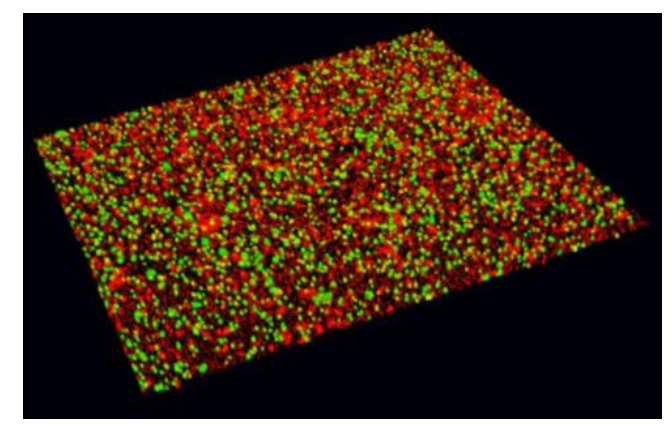

BAR modified NP $3 \mu \mathrm{M}$

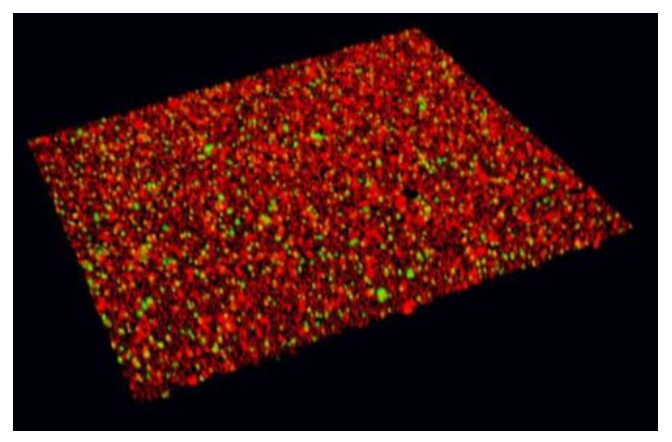

Fig. 19. Confocal microscopy images showing untreated, free BAR treated and BAR-modified NP treated biofilms.

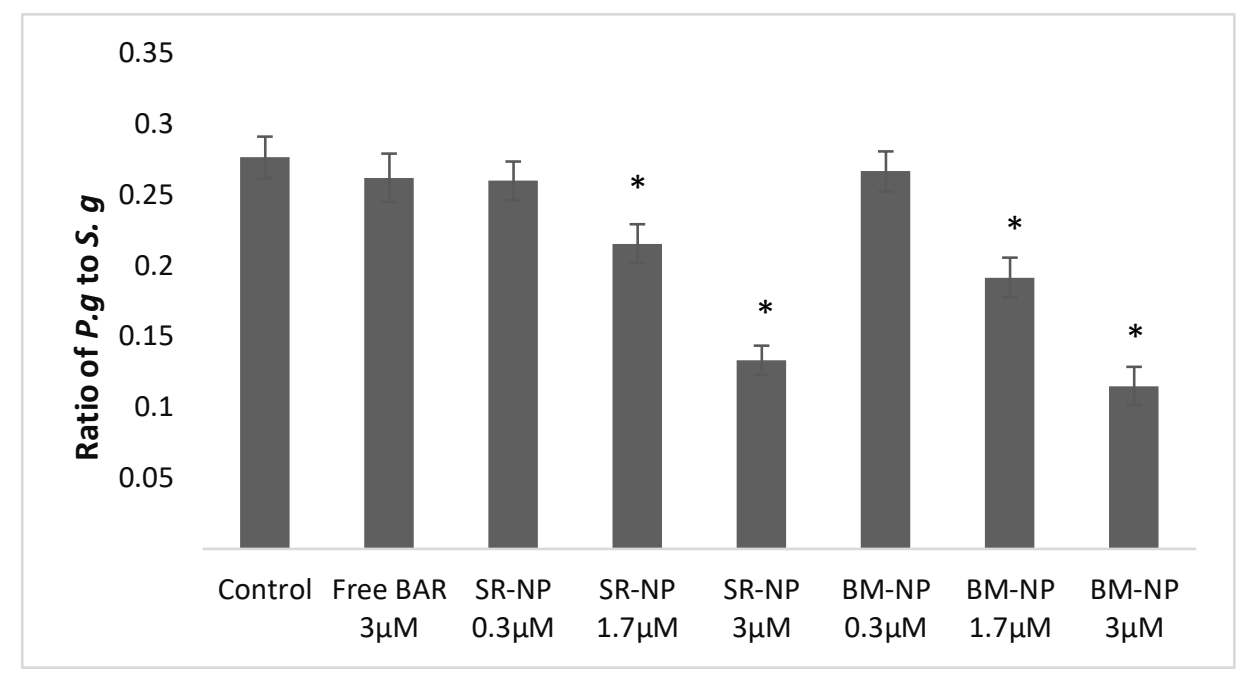

Fig. 20. Ratio of $P$. gingivalis and $S$. gordonii microcolonies treated with free BAR, Sustained released (SR) NPs, BAR modified (BM) NPs. *, the ratio was statistically significant relative to control and free BAR treated biofilms. $(\mathrm{P}<0.05)$ 


\section{Expression of CafA adhesion for targeting nanoparticles}

Insert gene was amplified using PCR. Gel electrophoresis of the PCR products showed an acceptable size of approximately 2500 base pairs (Fig 21)

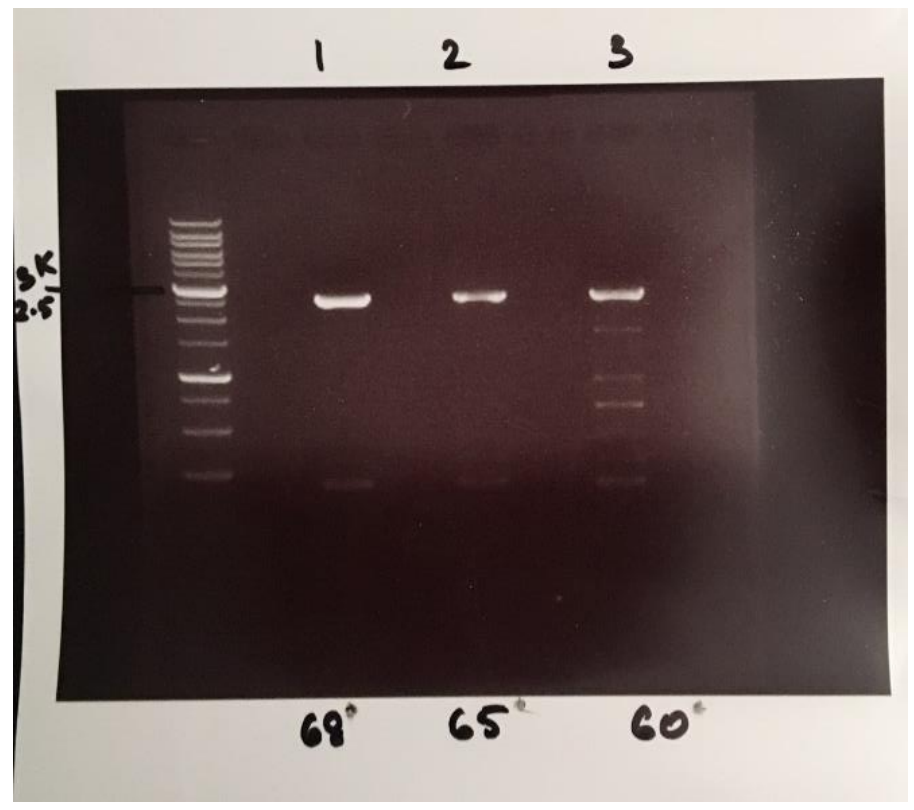

Fig 21. Gel electrophoresis showing PCR products amplifying cafA gene.

This insert DNA was the digested and ligated with PQE60 vector and successfully electroporated into XL1 competent cells. Plasmid from recombinant E. coli was sent to sequencing. A BLAST ${ }^{\circledR}$ search of the sequencing results showed that the recombinant $E$. coli was coding for collagen binding protein and not CafA. 


\section{CHAPTER 5}

\section{DISCUSSION}

One of the most common infectious diseases of the oral cavity, periodontitis, results in tooth loss and significantly affects patient quality of life. Periodontitis is considered to be a public health problem and a significant economic investment is made on treatment and prevention. The multifactorial disease etiology and, treatments based on limiting the disease progression combined with the decreased bioavailability of antibiotics in the diseased site have all resulted in difficulty managing periodontal diseases effectively.

Periodontitis is an inflammatory disease most often associated with the overgrowth of $P$. gingivalis. The primary niche for $P$. gingivalis is in the anaerobic sub gingival pocket of the oral cavity; however the initial colonization occurs when $P$. gingivalis interacts with oral commensals. One such interaction important for $P$. gingivalis colonization is the species specific interaction with S. gordonii. Previous studies have identified that this interaction is mediated by Mfal of $P$. gingivalis and $\mathrm{SspB}$ polypeptide of $S$. gordonii. This initial interspecies interaction represents a potential target for limiting $P$. gingivalis colonization and prevent periodontal diseases. A synthetic analog of the SspB polypeptide designated BAR was identified. BAR was successful in limiting $P$. gingivalis colonization both in vitro and in vivo. While BAR is effective in limiting the initial colonization of $P$. gingivalis, it was shown to be less effective against well-established and complex biofilms. Our preliminary studies revealed that a prolonged exposure of BAR can significantly inhibit $P$. gingivalis in an established two species $P$. gingivalis/ $S$. gordonii biofilm. In this 
study, we hypothesized that targeted PLGA nanoparticles encapsulating BAR peptide may increase the potency of BAR by providing a higher localized concentration of BAR for a prolonged duration of time.

We successfully and reproducibly synthesized NPs that encapsulate BAR. BAR encapsulated NPs resulted in a gradual release of BAR. This suggest a therapeutic approach to release BAR to inhibit $P$. gingivalis. NPs continued to release BAR up to 24 hours but the amounts were significantly low. We envision that surface modification of these NPs will help not just to target them but also prolong the release for up to 24 hours. Various polymer blends like PLA, PLCL or different lactide to glycolide ratio of PLGA can be used for synthesis of NPs to prolong the release beyond 24 hours. Our goal is to achieve an optimum concentration of BAR for 24 hours since our ultimate goal is to use these NPs therapeutically.

In addition to prolonging BAR delivery, another approach is to localize NPs in the oral cavity for longer duration. To achieve this and maximize NP efficacy, it is important that the NPs are present in areas of the oral cavity where $P$. gingivalis is present. To target NPs to these niches, a surface adhesin CafA found on A. oris can be used. CafA is a surface protein found on A. oris which helps it to coaggregate with streptococci. CafA reacts with a surface carbohydrate that is expressed by many of the streptococcus species that $P$. gingivalis interacts with.

One strategy is to surface modify NPs with CafA to target them to region where oral streptococci and $P$. gingivalis are present in the oral cavity. Since CafA is not commercially available, the gene that encodes for CafA was amplified and expressed in $E$. coli. The resulting recombinant E. coli was unsuccessful in expressing CafA. The potential 
reason for the failure in exression of CafA was a mis-anotation of cafA gene in oralgen. Further experiments are underway to design new primers to try create a new recombinant E. coli to express CafA. If there is difficulty in expressing CafA other proteins like Fab fragments from existing anti-SspB antibodies can be used to surface modifiy NPs.

Nanofibers are polymeric fibers synthesized by electrospinning of the polymer. Electrospinning is rather inexpensive and user friendly process used to fabricate nanofibers. Fibers are traditionally used in gingival sulcus to provide a better localized concentration of drugs. Different fibers used in local periodontal therapy are tetracycline fiber, doxycycline polymer, chlorhexidine chip, etc. The ability to use BAR fibers within the sulcus which is the primary niche of $P$. gingivalis will help in improved local concentration of BAR and better inhibition of $P$. gingivalis.

Electrospun nanofibers encapsulating BAR had a higher payload but the release kinetics showed poor release in the first 24 hours. While this suggests that NFs are capable of releasing BAR over a period of weeks or months, they were unable to deliver at least the $\mathrm{IC}_{50}$ concentration of $\mathrm{BAR}$. The reason why NFs were unable to release higher concentration of BAR is not known at this time. Various polymers can be tried to optimize the release kinetics of the NFs. The ease of synthesis and the ability to use in the subgingival pocket makes NFs a very good candidate for delivery of BAR.

Our results show that a 1 hour treatment using a molar equivalent of BAR-NP resulted in significantly higher inhibition of $P$. gingivalis in an established biofilm than a 3 hour treatment using free BAR. We believe that the greater efficacy of BAR-NPs will be helpful in developing NPs in therapeutic formulations such as a toothpaste, mouth rinse or 
chewing gum. Surface modification to bind to other oral bacteria might further help in longer bioavailability and higher local concentration of BAR.

BAR-modified NPs have also shown to inhibit $P$. gingivalis in an established biofilm. Together these experiments suggest that NPs can deliver higher localized concentration of BAR sufficient to inhibit $P$. gingivalis in an established two species biofilm. Our results suggest that use of nanotechnology is a novel approach which can successfully be used to prevent oral diseases by limiting pathogen colonization of the oral cavity. We also understand that periodontal diseases have a multispecies etiology. The versatility of nanotechnology to use multiple proteins in the same nanoparticle formulation will allow to target other species of bacteria to limit periodontitis.

Future studies will focus on expression of CafA adhesin which will then be biotinylated and conjugated to avidin-NPs as done in BAR modification of NPs. If necessary, the level of surface associated CafA will be adjusted to increase or decrease the retention on streptococci. Once appropriate retention is achieved, the controlled release profile will be assessed to determine if surface modification has affected the release kinetics. Additional studies will focus on optimizing the total payload by various ratios of polymer formulations used for nanoparticle synthesis. Further experiments will test the ability of targeted sustained release BAR-NPs to reduce $P$. gingivalis colonization both in vitro and in vivo. Additionally, BAR-NPs can be tested on more complex three species biofilms. Following this, experiments will be done to examine the toxicity of targeted sustained release NPs against human gingival cells and methods to formulate NP preparations will be studied. We are also working on more economical alternatives like peptidomimetics of BAR. If successful in identifying a peptidomimetic for BAR the same 
nanotechnology can be used as a delivery vehicle for these peptidomimetics to inhibit $P$. gingivalis. Our long term goal is to develop these NPs to be tested for efficacy in humans in a clinical trial. Studies will be focused to test the toxicity of NPs against human oral gingival and innate immune cells. Once NPs are shown to be non-toxic they will be tested for their efficacy to prevent $P$. gingivalis colonization and re-colonization after treatment. 


\section{REFERENCES}

1. Newman MG, Carranza FA, Takei H, Klokkevold PR. Carranzas clinical Periodontology. 10th ed. Elsevier health sciences; 2006.

2. Sheiham, A., \& Netuveli, G. S. (2002). Periodontal diseases in Europe. Periodontology 2000, 29(1), 104-121.

3. Corbet, E. F., Zee, K. Y., \& Lo, E. (2002). Periodontal diseases in Asia and Oceania. Periodontology 2000, 29(1), 122-152.

4. Dye, B. A. (2012). Global periodontal disease epidemiology. Periodontology 2000, 58(1), 10-25.

5. Eke, P. I., Dye, B. A., Wei, L., Slade, G. D., Thornton-Evans, G. O., Borgnakke, W. S., ... \& Genco, R. J. (2015). Update on prevalence of periodontitis in adults in the United States: NHANES 2009 to 2012. Journal of periodontology, 86(5), 611 622.

6. Kim, J., \& Amar, S. (2006). Periodontal disease and systemic conditions: a bidirectional relationship. Odontology, 94(1), 10-21.

7. Scannapieco, Frank A. (2013) "The oral microbiome: Its role in health and in oral and systemic infections." Clinical Microbiology Newsletter 35.20: 163-169.

8. Kaur, S., Bright, R., Proudman, S. M., \& Bartold, P. M. (2014). Does periodontal treatment influence clinical and biochemical measures for rheumatoid arthritis? A systematic review and meta-analysis. In Seminars in Arthritis and Rheumatism. WB Saunders.

9. Genco, R. J., \& Borgnakke, W. S. (2013). Risk factors for periodontal disease. Periodontology 2000, 62(1), 59-94.

10. Reuland-Bosma, W., \& Dijk, J. (1986). Periodontal disease in Down's syndrome: a review. Journal of clinical periodontology, 13(1), 64-73.

11. Hasan, A., \& Palmer, R. M. (2014). A clinical guide to periodontology: Pathology of periodontal disease. British dental journal, 216(8), 457-461.

12. Duncan, T. B. (2009). The Pathogenesis and Treatment of Periodontal Disease.

13. Waters, C. M., \& Bassler, B. L. (2005). Quorum sensing: cell-to-cell communication in bacteria. Annu. Rev. Cell Dev. Biol., 21, 319-346.

14. Huang, R., Li, M., \& Gregory, R. L. (2011). Bacterial interactions in dental biofilm. Virulence, 2(5), 435-444.

15. Rosan, B., \& Lamont, R. J. (2000). Dental plaque formation. Microbes and infection, 2(13), 1599-1607.

16. Huang, R., Li, M., \& Gregory, R. L. (2011). Bacterial interactions in dental biofilm. Virulence, 2(5), 435-444. 
17. Ritz, H. L. (1967). Microbial population shifts in developing human dental plaque. Archives of Oral Biology, 12(12), 1561-1568.

18. Stanley, N. R., \& Lazazzera, B. A. (2004). Environmental signals and regulatory pathways that influence biofilm formation. Molecular microbiology, 52(4), 917924.

19. Rosan, B., \& Lamont, R. J. (2000). Dental plaque formation. Microbes and infection, 2(13), 1599-1607.

20. Kaplan, J. Á. (2010). Biofilm dispersal: mechanisms, clinical implications, and potential therapeutic uses. Journal of dental research, 89(3), 205-218.

21. Donlan, R. M. (2002). Biofilms: microbial life on surfaces. Emerg Infect Dis, 8(9).

22. Rosier, B. T., De Jager, M., Zaura, E., \& Krom, B. P. (2014). Historical and contemporary hypotheses on the development of oral diseases: are we there yet?. Frontiers in cellular and infection microbiology, 4, 92.

23. Loesche, W. J. (1975). Chemotherapy of dental plaque infections. Oral sciences reviews, 9, 65-107.

24. Kuramitsu, H. K., He, X., Lux, R., Anderson, M. H., \& Shi, W. (2007). Interspecies interactions within oral microbial communities. Microbiology and molecular biology reviews, 71(4), 653-670.

25. Socransky, S. S., Haffajee, A. D., Cugini, M. A., Smith, C., \& Kent, R. L. (1998). Microbial complexes in subgingival plaque. Journal of clinical periodontology, 25(2), 134-144.

26. Datta, H. K., Ng, W. F., Walker, J. A., Tuck, S. P., \& Varanasi, S. S. (2008). The cell biology of bone metabolism. Journal of clinical pathology, 61(5), 577-587. How, K. Y., Song, K. P., \& Chan, K. G. (2016). Porphyromonas gingivalis: an overview of periodontopathic pathogen below the gum line. Frontiers in microbiology, 7.

27. How, K. Y., Song, K. P., \& Chan, K. G. (2016). Porphyromonas gingivalis: an overview of periodontopathic pathogen below the gum line. Frontiers in microbiology, 7, 53.

28. Hajishengallis, G., Darveau, R. P., \& Curtis, M. A. (2012). The keystonepathogen hypothesis. Nature Reviews Microbiology, 10(10), 717-725.

29. Lamont, R. J., Gil, S., Demuth, D. R., Malamud, D., \& Rosan, B. (1994). Molecules of Streptococcus gordonii that bind to Porphyromonas gingivalis. Microbiology, 140(4), 867872.

30. Brooks, W., Demuth, D. R., Gil, S., \& Lamont, R. J. (1997). Identification of a Streptococcus gordonii $\mathrm{SspB}$ domain that mediates adhesion to Porphyromonas gingivalis. Infection and immunity, 65(9), 3753-3758.

31. Chung, W. O., Demuth, D. R., \& Lamont, R. J. (2000). Identification of a Porphyromonas gingivalis Receptor for the Streptococcus gordonii $\mathrm{SspB}$ Protein. Infection and immunity, 68(12), 6758-6762.

32. Lamont, R. J., El-Sabaeny, A., Park, Y., Cook, G. S., Costerton, J. W., \& Demuth, D. R. (2002). Role of the Streptococcus gordonii $\mathrm{SspB}$ protein in the development of Porphyromonas gingivalis biofilms on streptococcal substrates. Microbiology, 148(6), 1627-1636.

33. Lamont, R. J., \& Hajishengallis, G. (2015). Polymicrobial synergy and dysbiosis in inflammatory disease. Trends in molecular medicine, 21(3), 172-183. 
34. Demuth, D. R., Irvine, D. C., Costerton, J. W., Cook, G. S., \& Lamont, R. J. (2001). Discrete protein determinant directs the species-specific adherence of Porphyromonas gingivalis to oral streptococci. Infection and immunity, 69(9), 5736-5741.

35. Daep, C. A., James, D. M., Lamont, R. J., \& Demuth, D. R. (2006). Structural characterization of peptide-mediated inhibition of Porphyromonas gingivalis biofilm formation. Infection and immunity, 74(10), 5756-5762.

36. Daep, C. A., Lamont, R. J., \& Demuth, D. R. (2008). Interaction of Porphyromonas gingivalis with oral streptococci requires a motif that resembles the eukaryotic nuclear receptor box protein-protein interaction domain. Infection and immunity, 76(7), 3273-3280.

37. Daep, C. A., Novak, E. A., Lamont, R. J., \& Demuth, D. R. (2011). Structural dissection and in vivo effectiveness of a peptide inhibitor of Porphyromonas gingivalis adherence to Streptococcus gordonii. Infection and immunity, 79(1), 67-74.

38. Allaker, R. P. (2010). The use of nanoparticles to control oral biofilm formation. Journal of dental research, 89(11), 1175-1186.

39. Kumari, A., Yadav, S. K., \& Yadav, S. C. (2010). Biodegradable polymeric nanoparticles based drug delivery systems. Colloids and Surfaces B:

Biointerfaces, 75(1), 1-18.

40. Danhier, F., Ansorena, E., Silva, J. M., Coco, R., Le Breton, A., \& Préat, V. (2012). PLGA-based nanoparticles: an overview of biomedical applications. Journal of controlled release, 161(2), 505-522.

41. Steinbach, J. M. (2015). Protein and oligonucleotide delivery systems for vaginal microbicides against viral STIs. Cellular and Molecular Life Sciences, 72(3), 469503.

42. Martin, D. T., Steinbach, J. M., Liu, J., Shimizu, S., Kaimakliotis, H. Z., Wheeler, M. A., ... \& Weiss, R. M. (2014). Surface-Modified Nanoparticles Enhance Transurothelial Penetration and Delivery of Survivin siRNA in Treating Bladder Cancer. Molecular cancer therapeutics, 13(1), 71-81.

43. Makadia, H. K., \& Siegel, S. J. (2011). Poly lactic-co-glycolic acid (PLGA) as biodegradable controlled drug delivery carrier. Polymers, 3(3), 1377-1397.

44. Asmatulu, R., Fakhari, A., Wamocha, H. L., Chu, H. Y., Chen, Y. Y., Eltabey, M. M., ... \& Ho, J. C. (2009). Drug-carrying magnetic nanocomposite particles for potential drug delivery systems. Journal of Nanotechnology, 2009.

45. Hu, X., Liu, S., Zhou, G., Huang, Y., Xie, Z., \& Jing, X. (2014). Electrospinning of polymeric nanofibers for drug delivery applications. Journal of Controlled Release, 185, 12-21.

46. Hrib, J., Sirc, J., Hobzova, R., Hampejsova, Z., Bosakova, Z., Munzarova, M., \& Michalek, J. (2015). Nanofibers for drug delivery-incorporation and release of model molecules, influence of molecular weight and polymer structure. Beilstein journal of nanotechnology, 6(1), 1939-1945. 
47. Son, Y. J., Kim, W. J., \& Yoo, H. S. (2014). Therapeutic applications of electrospun nanofibers for drug delivery systems. Archives of pharmacal research, 37(1), 69-78.

48. Frisch, J., Levin, M. P., \& Bhaskar, S. N. (1968). The use of tissue conditioners in periodontics. Journal of periodontology, 39(6), 359-361.

49. Qie, Y., Yuan, H., von Roemeling, C. A., Chen, Y., Liu, X., Shih, K. D., ... \& Kim, B. Y. (2016). Surface modification of nanoparticles enables selective evasion of phagocytic clearance by distinct macrophage phenotypes. Scientific reports, 6 .

50. Li, J., Wang, Y., Liang, R., An, X., Wang, K., Shen, G., ... \& Tao, J. (2015). Recent advances in targeted nanoparticles drug delivery to melanoma. Nanomedicine: Nanotechnology, Biology and Medicine, 11(3), 769794.

51. Chen, H., Xie, L. Q., Qin, J., Jia, Y., Cai, X., Nan, W., ... \& Zhang, Q. Q. (2016). Surface modification of PLGA nanoparticles with biotinylated chitosan for the sustained in vitro release and the enhanced cytotoxicity of epirubicin. Colloids and Surfaces B: Biointerfaces, 138, 1-9.

52. Reardon-Robinson, M. E., Wu, C., Mishra, A., Chang, C., Bier, N., Das, A., \& Ton-That, H. (2014). Pilus hijacking by a bacterial coaggregation factor critical for oral biofilm development. Proceedings of the National Academy of Sciences, 111(10), 3835-3840. 


\section{CURRICULUM VITAE}

NAME: $\quad$ Ranjith Radha Krishnan

ADDRESS: Dept. of Oral Immunology and Infectious Diseases

University of Louisville School of Dentistry

501 South Preston Louisville, KY 40202

EDUCATION \& TRAINING

Bachelor of Dental Surgery

Rajiv Gandhi University of Health Sciences, Karnataka, India.

2007-12

\section{PROFESSIONAL SOCIETIES}

American Association for Dental Research (AADR)

January 2015 - Ongoing

International Association for Dental Research (IADR)

January 2015 - Ongoing

\section{PRESENTATIONS}

Research! Louisville, Louisville, KY October 2015, October 2016

Poster Presentation: Synthesis and Characterization of Targeted BAR-modified Sustained Release PLGA Nanoparticles to Inhibit Porphyromonas gingivalis Biofilm Formation.

Hinman Student Research Symposium, Memphis, TN October 2015

Poster Presentation: Synthesis and Characterization of Targeted BAR-modified Sustained Release PLGA Nanoparticles to Inhibit Porphyromonas gingivalis Biofilm Formation.

National BDS Students Seminar held at Saveetha Dental College, Chennai December 2010.

Paper presentation: Detection Tests for Oral Cancer. 